\title{
Recipes for a Successful Exit for Clean- and Hard-tech Startups
}

Soh Young In* (Stanford University, si2131@stanford.edu)

Ashby Monk (Stanford University, amonk@stanford.edu)

Justine Lee (Stanford University, ljustine@stanford.edu)

November 2020

\section{[Working Paper Draft: Do not copy, cite, or distribute without permission of the authors]}

This study demonstrates the combinations of multiple causal factors that formulate a startup's strategy to successfully "exit", namely "recipes for a successful exit," in the clean- and hard-tech sector. We identify seven key causal factors (i.e., causal conditions) that impact startup success, including commercial readiness, investor interactions, favorable industry, non-financial support, straightforward development path, experienced team, and visibility to investors. We also investigate the combinations of selective causal conditions that can provide further synergetic impact. We conduct the fuzzy-set qualitative comparative analysis (fsQCA) on seven US cleanand hard-tech startups that exited between 2005 and 2016. The successful companies all demonstrate distinctive characteristics based on three general categories (1) robust ecosystem; (2) heavy-lifting team; or (3) external opportunity. Across these three categories, commercial readiness and strong investor interactions are necessary conditions for all exit cases. But there are important differences that drive success in each category, such as the interaction with non-financial support (in the robust ecosystem case), experienced team (in the heavy-lifting team case), and favorable industry (in the external opportunity case). Our findings are meant to support entrepreneurs in reaching an exit by optimizing the given internal and external circumstances, and policymakers to build a robust ecosystem that can increase the success rate of the clean- and hardtech development.

Keywords: entrepreneurship; tech-to-market pathway; exit strategy; fuzzy-set qualitative comparative analysis; clean technologies; hard technologies 


\section{Introduction}

Clean technologies ("clean-tech") and hardware technologies ("hard-tech") companies advance natural science-based knowledge, such as materials science, chemistry, physics, or biology, and their innovations are physical (i.e., not purely based on software, business, and financial services innovations). The development of clean- and hard-tech has been key to combatting climate change, facilitating the transition to a low-carbon and climate-resilient economy. Yet, clean and hard-tech startups are often perceived as highly risky and uncertain, as their development process is often stalled by what has become known as a "valley of death" (VoD), where breakthrough innovation fails due to severe funding shortages at critical stages of companies' development (Heap, Pless, \& Aieta, 2013; Rai, Funkhouser, Udwin, \& Livingston, 2015; Weyant J. P., 2011).

Because of the importance of clean- and hard-tech technologies in our collective wellbeing, researchers have sought to identify the factors that can increase the likelihood of their success, which could help to attract investors to support these firms through the VoD. Many studies propose policy and regulatory interventions or assess their effectiveness in increasing clean- and hard-tech investment and survival rates (Bürer \& Wüstenhagen, 2009; Tsoutsos \& Stamboulis, 2005). In fact, the industry often receives strong policy and regulatory support due to its public nature and positive environmental externalities. But, the policy support often comes in peaks and valleys, which intrinsically conflict with the needs of the long-term nature of the clean- and hard-tech development process (Nemet, 2009; Doblinger, Dowling, \& Helm, 2013; Hoppmann, Peters, Schneider, \& Hoffmann, 2013). Alternatively, studies like Bose, Gao, Moshkin, Patel, \& Laipple (2018), Monk, Kearney, Seiger, \& Donnelley (2015), Mazzucato \& Semieniuk (2018), Weyant, $\mathrm{Fu}, \&$ Bowersock (2018) and In \& Monk (2020) discuss how to strengthen the understanding--or address the misperceptions--of cleantech development and identify the synergistic links in the cleantech ecosystem. In \& Monk (2020), for instance, discuss the need to extend the boundary of

existing research beyond assessing the economic viability of current technology and instead focus on ways to effectively intermediate between entrepreneurs and suitable investors, for instance institutional investors with long-term perspectives. Other studies focus on developing firm-centric factors such as technological leadership and entrepreneurs' strategic management capabilities (Garfield, Moore, \& Adams, 2019; Bjornali \& Ellingsen, 2014). 
Despite this focus and indeed progress, existing research does not adequately address the significant challenges facing clean- and hard-tech entrepreneurs themselves. In particular, previous studies focus on testing the effect of a specific factor to the outcome, while neglecting a deeper understanding of the process of building a company over time, which includes a focus on both the external ecosystem and internal organization (and the interplay between the two). Sadly, prior research hasn't fully delivered on this objective for two reasons: First, previous studies' selection of causal factors has been biased towards the traditional, financial factors that are easily quantified and explicit, such as how long and how much investment will optimize investment returns. While interesting, many researchers advocate exploring non-financial factors related to the ecosystem, especially those that can reinforce startups' competitive advantages (e.g., Knox-Hayes (2010), Knight (2010), Saxenian \& Sabel (2008)). Knight (2010) also highlights the shift of focus from seeking measurable drivers of innovation to examining the characteristics underpinning innovation ecosystems, and we believe this approach should be more thoughtfully applied to the world of clean- and hard-tech entrepreneurism. Second, extant studies are limited to assessing the impact of a single factor, while a startup's success is the combined consequence of multiple causal factors. Del Sarto, Di Minin, Ferrigno, \& Piccaluga (2019) review literature studying the relationship between a specific internal factor and a startup's survival rate (e.g. Boyer \& Blazy (2014), Yang, Bossink, \& Peverelli (2017)), and identify that the previous studies are limited to assessing a single factor in isolation. Similarly, Weyant, Fu, \& Bowersock (2018) point out the lack of comprehensive understanding of conjunctional impacts of the ecosystem approach: they argue that while efforts coming from policymakers, investors, and business-related organizations to bridge cleantech VoD are all highly encouraging, they should be comprehensively considered, not examined in isolation.

Encouragingly, Del Sarto, Di Minin, Ferrigno, \& Piccaluga (2019) have begun to address this issue in their research. The authors investigate the impact of four internal and non-financial factors (R\&D activity, advertising activity, export activity, and human capital) on startups' survival and also which combination of these four factors can amplify the impact. They study 38 startups accelerated in Italy in 2013, and analyze the cases using fuzzy-set qualitative comparative analysis (fsQCA) to capture multiple factors' combined impact. This research has serviced as an inspiration for this paper, mirroring their approach and methodology. Notwithstanding, their approach has two limitations in our opinion. First, their study focusses on internal factors and 
interactions among them. However, as previous studies on public policy and clean tech ecosystems highlight, we should consider external and internal factors and their combinations. Second, the focus of their study is not on the clean- and hard-tech sector. The clean and hard-tech sector requires subtle attention to its unique challenges. Because technology should be accelerated by building tangible assets, it often requires long-term and large-scale capital investment.

This study seeks to fill the gaps in prior literature by investigating critical causal conditions that can determine successful exits of clean- and hard-tech startups. The aim is to formulate "recipes for a successful exit" that can be adopted by future generations of entrepreneurs and investors. A successful exit refers to a case in which entrepreneurs, and their investors, make a substantial profit by reducing or liquidating their ownership stake in a business they founded. Our main research focus is the causal conditions, alone or through combined effects, that played a key role in successful clean and hard-tech exits between 2005 and 2016. Our paper's contribution to the existing literature on clean- and hard-tech entrepreneurship is threefold: First, through literature review and inductive thematic analysis, we identify seven key causal conditions that contribute to successful exits. Second, we conduct semi-structured interviews with founders and early employees to build in-depth case knowledge of eleven early-stage clean- and hard-tech companies. These eleven cases provide empirical evidence to refine and support our understanding of the seven causal factors. Lastly, we conduct a fsQCA to identify distinct "exit recipes," or pathways, that distinguish successful cases from unsuccessful cases in our study. We also discuss the implications of past successful startups to current entrepreneurs, incubator programs, and policymakers. Thus, this paper seeks to clarify successful exit mechanisms, which will in turn encourage more entrepreneurial entry as more exits occur, and thus lead to the emergence of more cleantech innovation (Parastuty, Breienecker, Scharz, \& Harms, 2016; DeTienne, 2010).

This paper is structured as follows. Section 2 identifies the knowledge gaps in effectively supporting clean- and hard-tech entrepreneurs by discussing the conventional Silicon Valley model's failure, undervalued conjunctional causation of factors, and excessive reliance on direct governmental support. Section 3 investigates critical factors that lead to successful investment outcomes and build seven key factors to be tested. Section 4 explains the rationale behind the case selection and the methodological approach. Section 5 reveals three recipes for successful exits based on the analysis of cases and discusses in-depth dynamic relationships among seven causal 
factors. Section 6 concludes with implications for an effective support system for cleantech entrepreneurs and building a supportive ecosystem, limitations, and future research suggestions.

\section{Point of Departure}

The technology-to-market ("tech-to-market") pathway starts with a startup developing an idea and then productizing that idea before bringing it to market, finding a fit, establishing the steps needed for profitability, and, ultimately, success. Along this path, founders are continuously de-risking different aspects of their projects and companies. Unfortunately, clean- and hard-tech entrepreneurs face a much longer and steeper path to success. Which is based on the difficulties of building clean- and hard-tech technology and its associated infrastructure. The "fail fast, fail often" spirit so widespread in Silicon Valley often fails in clean- and hard-tech industries, where failures can be incredibly expensive, and so the typical de-risking strategies of VC/PE funds are not fully effective in this industry (Gaddy, Sivaram, \& O'Sullivan, 2016). Generally, developing disruptive hard-tech requires more time and costs to iterate on a physical product than a software one. The cleantech development cycle should complete by building/fabricating an energy infrastructure asset and penetrating the commodity market (Rosenthal, 2017).

Scholars classified these factors into two groups: external and internal. Internal factors include R\&D resources (Del Sarto, Di Minin, Ferrigno, \& Piccaluga, 2019; Yang, Bossink, \& Peverelli, 2017), human capital (Song, Podoynitsyna, Van Der Bij, \& Halman, 2008; Mason \& Stark, 2004; Gulati \& Higgins, 2003; Burton, Sørensen, \& Beckman, 2001; Marino \& De Noble, 1997; Zacharakis \& Meyer, 2000), and internal finance. External factors include policies and regulations (Malen \& Marcus, 2016; Goldman, Fennell, Miller, Davis, \& White, 2017), public acceptance (Lettice, Smart, Baruch, \& Johnson, 2012), and other macroeconomic conditions (Fernandez, Stein, \& Lo, 2012; Gaddy, Sivaram, \& O’Sullivan, 2016). Thus far, however, previous research tend to focus one or the other, and even these sided studies largely focus on external factors (Del Sarto, Di Minin, Ferrigno, \& Piccaluga, 2019; Bjornali \& Ellingsen, 2014). Indeed, hard-tech companies generally face far more regulatory and commercial scrutiny because hardtech innovations tend to have real-world physical impacts and necessities (to health, to safety, to a supply chain/manufacturing line, etc.). The industry receives strong policy and regulatory support, such as subsidies, tax equity credits, and other incentives to make these technologies more economically viable. However, projects under intense domestic and global policy influence are 
also exposed to political uncertainties. For example, our case study interviewees frequently use the words "solar coaster," which conventionally refers to the cyclical nature of the rebates and financial incentives that often support the viability of some of these technologies. But policydriven growth tends to raise speculation among investors as to a project's actual market competitiveness and resilience, as many worry (rightfully) what will happen if or when favorable policies are eased (Nemet, 2009; Doblinger, Dowling, \& Helm, 2013; Hoppmann, Peters, Schneider, \& Hoffmann, 2013). Because the external factors are often beyond the control of entrepreneurs and investors, tscholars' focus has begun to shift towards internal factors. However, very little research has been done to date. For example, Bjornali \& Ellingsen (2014) find that there are surprisingly few studies that identify critical factors affecting the growth of clean-tech startups, and that almost of all these studies concentrate on policies and regulations, not firm-centric factors. The consideration of firm-centric (or internal perspective) factors are frequently discussed in the resource-based view of the firm, whose empirical evidence is however relatively limited (YangC., BossinkB., PeverelliP., 2017).

Research is needed that elaborates how clean- and hard-tech entrepreneurs become innovative, economically viable, and self-reliant, i.e., not entirely dependent on policy support. This paper seeks to fill this void by investigating the conjunctional causation of multiple factors (i.e., causal conditions), including financial vs. non-financial, tangible vs. intangible, internal vs. external. Then, we investigate the combinations of selective causal conditions that can amplify a startup's success. In this regard, we test factors that are at different levels: factors are at an individual level (e.g., entrepreneur's capabilities), a firm level (e.g., a firm's capabilities, especially governance and management-related), and a system level (e.g., policies, regulations). Yet, the measure of these factors is from a startup's standpoint. In other words, we can only say there was a favorable policy when the policy is explicitly and positively related to the technology and business of the startup of our interest. Moreover, we comprehensively consider traditional factors typically assessed during investors' due diligence (e.g., commercial readiness, management team, market adoption) and non-traditional factors, such as how entrepreneurs build networks with investors.

This approach is important for three key reasons. First, these factors are considered nontraditional resources that are frequently discussed as important considerations of a startup's development and survival in practice but their financial effects have not been clearly validated and 
accepted in the literature. Existing literature and knowledge of exit mechanisms is heavily weighted toward how investors evaluate and mitigate the risks but less on the process that entrepreneurs or startups can de-risk (Polzin, 2017). However, non-financial factors can also play a critical role in determining the firm's ability to overcome obstacles in their pathway to a successful exit. While demonstrating financial performance and raising sufficient fund to grow is essential for entrepreneurial success, the firms' tendency to hyperfocus on imminent financial obstacles largely governs the short-sighted business strategies and prevents firms from giving sufficient attention to other vital causal factors required for a successful exit. (Porter, 1992) analyzes the investment patterns of US corporations and suggests that "the US system favors acquisitions, which involve assets that can be easily valued over internal development projects that are more difficult to value" (Porter, 1992, p. 73). The underlying system-wide preference for tangible assets over intangible assets may have influenced the financial hyperfocus of entrepreneurial firms. Vuong, Do, \& Vuong (2016) and Vuong \& Napier (2014) discuss how a firm's overemphasis on financial factors such as resource scarcity can turn entrepreneurship into a resource-acquiring game, which can be coupled with "persistent lack of innovation capacity, leading a venture to constantly declining efficiency and finally financial distress (Vuong, Do, \& Vuong, 2016, p. 5). Wang, Li, \& Jiang (2019) also find that most existing literature related to entrepreneurial business ties has an overemphasis on the beginning resource acquiring phase, disregarding "other deeper phases in resource management process." The latest business trends demonstrate the growing importance of other factors such as non-financial indicators in determining the company’s overall performance (Benková, Gallo, Balogová, \& Nemec, 2020).

Second, this study investigates the conjunctional causal effects of multiple factors that can drive a firm to its successful exit but lack empirical evidence from previous literature. Kaplan (2009) highlights the impact of conjunctional causation of intangible factors, suggesting that "improvements in intangible assets affect financial outcomes through chains of cause-and-effect relationships involving two or three intermediate stages" (p. 7). It is important to recognize the knowledge gap in understanding the impact of intangible, indirect assets on the firms' performance. Weyant, Fu, \& Bowersock (2018) also argue that conversations about initiatives, energy startup failures, or successful business deals, consider each focus area as a separate matter. A holistic understanding of the ecosystem is required - especially, integrated investors and entrepreneur 
relationships_ can help de-risk clean- and hard-tech innovation (In \& Monk, 2020; Bose S. , Gao, Moshkin, Patel, \& Laipple, 2018).

Third, although there is a broad consensus on the need to demonstrate successful exit mechanisms as good practice to complete the tech-to-market pathway (reference??), we see methodological concerns. Building and rationalizing a path to a successful exit is complicated and requires further academic scrutiny. The first challenge is that the definition and evaluation of a successful exit is controversial (Wennberg, 2011). The exit of a firm can refer to various outcomes, including exit from the market (Anderson \& Tushman, 2001; Carree, Verheul, \& Santarelli, 2011), discontinuance of operations (Carter, Williams, \& Reynolds, 1997), and business closure (Bates, 2005). Suppose, instead, the exit refers to offering a new stock, selling stocks, or transferring ownership of a company to another company. In that case, the exit can be further defined by the exit strategies, such as business closure due to acquisition, initial public offerings (IPO), strategic buyout, management buyout (MBO) or cessation of operations. Evaluating the exit performance is also subjective: in financial terms, the rate of return can help with an objective measurement, but investors often have different thresholds to determine a return that would be deemed successful. Moreover, we often see cases that investors evaluate a project as a successful case, while entrepreneurs from the same project have different opinions. ${ }^{1}$ It is because their objective functions are different - for instance, investors would see the rate of return on the investment while an entrepreneur of the project, for instance, thinks the way the project was developed and exited is not the optimal way of doing so.

Recognizing that a firm's performance depends entirely on the perspective of the person evaluating, we set the primary purpose of this paper to provide an in-depth understanding of the process to reach an exit. We use the fsQCA as the method of causal inference. ${ }^{2}$ We use FsQCA as

\footnotetext{
${ }^{1}$ Even within the investors, evaluation can vary. For instance, in a heavily diluted project, investors in earlier rounds can have high returns while investors joined later rounds are not. Likewise, the entrepreneur also has broad coverage, including founding members, business owners, management teams, and the nascent entrepreneur.

${ }^{2}$ First introduced in the mid-1980s by U.S. sociologist Charles Ragin (1987), fsQCA uses Boolean algebraic principles to formalize the logic of qualitative, case-comparative analysis. As a research approach, it has been widely applied across disciplines, including in business administration, public health, environmental science, management, and international relations (Baumgartner \& Thiem, 2017). Because fsQCA enables a systematic review of a larger set of cases while maintaining the advantages of in-depth case knowledge and contextual sensitivity, it has been described as bridging the qualitative/quantitative divide (Thomas, O'Mara-Eves, \& Brunton, 2014). In particular, fsQCA has been recognized to be well-suited for medium-range theory building and modest empirical testing (Jordan, Gross,
} 
a primary tool to answer this study's research question for three reasons: (1) fsQCA and other case comparative approaches can identify configurational solutions to an outcome (i.e., conjunctural causation); (2) fsQCA can identify multiple causal pathways that lead to the outcome of interest (i.e., equifinality); and (3) there is currently a dearth of successful cleantech hardware startups, making statistical methods an inappropriate approach.

First, fsQCA is uniquely suitable for accommodating phenomena with conjunctural causation. Conjunctural causation is the concept that an outcome depends on the co-occurrence of multiple causal conditions (Boudet, Jayasundera, \& Davis, 2011). Based on a literature review, it is hypothesized that there are complex interactions between the factors that influence how and whether cleantech hardware companies exit. For example, it may be necessary for a startup to have a certain threshold of TRL (technology readiness level) to exit successfully; but achieving this threshold TRL on its own, without other factors that support success, may not be sufficient for the successful outcome. In contrast with statistical methods that may be hampered by collinearity between individual variables, fsQCA is built on set theory, which expects that conditions can be related to one another in the form of intersections (Thomas, O’Mara-Eves, \& Brunton, 2014).

Second, fsQCA does not rule out equifinality, which is an advantage in the exploratory theory-building stage of research (Jordan, Gross, Javernick-Will, \& Garvin, 2011; Berg-Schlosser, De Meur, Rihoux, \& Ragin, 2009). Equifinality is the idea that there may be multiple causal pathways that lead to the same outcome of interest (Boudet, Jayasundera, \& Davis, 2011). This is especially important given the broad definition of cleantech and unique circumstances under which each company (or case) developed. If the underlying causal structure has multiple approaches to achieving success, then correlational analysis, which requires that a component's presence be associated with good outcomes and its absence to be associated with poorer outcomes, may not be suited for the study of this phenomenon (Thomas, O'Mara-Eves, \& Brunton, 2014). In contrast, configurational comparative approaches produce multiple recipes for further exploration and empirical testing.

Javernick-Will, \& Garvin, 2011; Berg-Schlosser, De Meur, Rihoux, \& Ragin, 2009). And because the logic used for variable identification, case selection, and case coding must be explicated during analysis, fsQCA elevates the transparency, replicability, and academic rigor of traditional case-study approaches. 
Third, fsQCA is an appropriate method for studying a phenomena with few examples (Del Sarto, Di Minin, Ferrigno, \& Piccaluga, 2019; Fiss, 2007). As discussed in the literature review, there are currently limited successful cases of cleantech hardware startups; however, there remains a need to stimulate innovations in clean technology in order to transition into a low-carbon economy. The small number of cases available for analysis make the case comparative approach for theory building a well-suited option.

\section{Hypothesis}

Based on our detailed review of the literature, we build seven hypotheses on causal conditions that can jointly contribute to the successful exit of clean- and hard-tech companies. The hypotheses are developed based on an extensive literature review and continuous conversations with investors to identify key factors in making investment decisions and evaluating their performance. Table 1 summarizes the definitions for each causal condition along with references to the supporting literature. Our hypotheses include not only factors whose impact and correlation to project success are well-established and broadly accepted, but also new factors that have not been critically assessed in due diligence or investment decision-making. The former includes external conditions, the maturity of a project's technology and commercial readiness, and management capabilities. The latter includes the project's visibility to potential investors, the network between the project's entrepreneurs and investors, the process of aligning key stakeholders of the project, and other nonfinancial supports. While these factors are known and used among experienced angel investors and venture capitalists, the impacts and mechanisms have not been systematically evidenced, discussed, and validated through academic literature.

Table 1. Literature support for the seven causal conditions identified

\begin{tabular}{|l|l|}
\hline Causal Conditions & Literature Support \\
\hline $\begin{array}{l}\text { (1) Favorable Industry - Contextual factors outside of } \\
\text { startup control are amenable and advantageous to the } \\
\text { type of innovation being developed. }\end{array}$ & $\begin{array}{c}\text { (Demirel, Li, Rentocchini, \& Tamvada, 2019); (Mazzucato \& } \\
\text { Semieniuk, 2018); (Hörisch, Kollat, \& Brieger, 2017); (Gorbolskaya, } \\
\text { 2015); (Criscuolo \& Menon, 2015); (Berrone, Fosfuri, Gelabert, \& } \\
\text { Gomez-Mejia, 2013); (Jaffe, 2012); (Bürer \& Wüstenhagen, 2009) }\end{array}$ \\
\hline $\begin{array}{l}\text { (2) Commercial Readiness - The startup's technology } \\
\text { has been developed to reach a maturity level such that } \\
\text { introduction to market is possible. }\end{array}$ & $\begin{array}{l}\text { (Hasenauer, Gschöpf, \& Weber, 2016); (Rahmany, et al., 2013); } \\
\text { 2002); (Stuart, Hoang, \& Hybels, 1999); (Lerner, 1994); (Austin, An }\end{array}$ \\
\hline
\end{tabular}




\begin{tabular}{|c|c|}
\hline & $\begin{array}{l}\text { event-study approach to measuring innovative output: The case of } \\
\text { biotechnology, 1993); (Kenney, 1988) }\end{array}$ \\
\hline $\begin{array}{l}\text { (3) Visibility to Potential Investors - The firm is } \\
\text { positioned such that successful contact between } \\
\text { potential investors and the firm is possible. }\end{array}$ & $\begin{array}{l}\text { (Zhong, Liu, Zhong, \& Xiong, 2018); (Powell, Koput, Bowie, \& Smith- } \\
\text { Doerr, 2002); (Florida \& Smith, Jr., Venture capital formation, } \\
\text { investment, and regional industrialization, 1993); (Florida \& Smith, Jr., } \\
\text { 1992) }\end{array}$ \\
\hline $\begin{array}{l}\text { (4) Interaction with Actual Investors - The nature and } \\
\text { frequency of dialogue between the firm and its } \\
\text { investors and the degree to which both parties' goals } \\
\text { aligned. }\end{array}$ & $\begin{array}{l}\text { (Demirel, Li, Rentocchini, \& Tamvada, 2019); (Demirel \& Parris, } \\
\text { 2015); (Hall \& Lerner, 2010); (Petkova, Wadhwa, Yao, \& Jain, 2014); } \\
\text { (Dakin, 2014); (Maurer \& Ebers, 2006); (Baum \& Silverman, 2004); } \\
\text { (Kelly \& Hay, 2003) }\end{array}$ \\
\hline $\begin{array}{l}\text { (5) Management Experience - Firm leaders have } \\
\text { previous experience on building and scaling a startup } \\
\text { or relevant industry experience. }\end{array}$ & $\begin{array}{l}\text { (Song, Podoynitsyna, Van Der Bij, \& Halman, 2008); (Mason \& Stark, } \\
\text { 2004); (Baum \& Silverman, 2004); (Gulati \& Higgins, 2003); (Burton, } \\
\text { Sørensen, \& Beckman, 2001); (Zacharakis \& Meyer, 2000) (Marino \& } \\
\text { De Noble, 1997) }\end{array}$ \\
\hline $\begin{array}{l}\text { (6) Non-financial Support-The firm is affiliated with } \\
\text { or uses resources from an outside program or } \\
\text { institution. }\end{array}$ & $\begin{array}{c}\text { (Song, Podoynitsyna, Van Der Bij, \& Halman, 2008); (Baum \& } \\
\text { Silverman, 2004); (Chamanski \& Waagø, 2001); (Baum, Calabrese, \& } \\
\text { Silverman, 2000); (Zahra \& Bogner, 2000); (Baum \& Oliver, 1991); } \\
\text { (McGee, Dowling, \& Megginson, 1995) }\end{array}$ \\
\hline $\begin{array}{l}\text { (7) Straightforward Development Path - The firm has } \\
\text { reached exit with minimal pivot activity. }\end{array}$ & (Bandera \& Thomas, 2019); (Crilly, 2018); (Leatherbee \& Katila, 2017) \\
\hline
\end{tabular}

\subsection{Favorable Industry}

Various contextual elements beyond the scope of a company's control, such as high public interest, environment, and many other social contextual factors, lead to the formation of favorable industry. Whether or not a company's technology belongs to the promising sector can affect the firm in expediting its innovation process. During Cleantech 1.0 and 2.0, capital investment in clean energy rapidly grew with increasing fuel costs, government policies supporting renewable energy, public interest for clean energy, and greater media exposure (Goldman, Fennell, Miller, Davis, \& White, 2017). It is also critical for investors that a system provides a promising outlook for the market growth and competitiveness of a technology that a company develops and sells. We investigate whether and which external conditions are likely to affect a firm's exit.

Our indicators for a favorable industry include: government interventions, market adoption, and other macroeconomic conditions. For example, energy and environmental policies actively create market opportunities for new technologies and advance energy systems, such as zero carbon emissions, energy reliability and resilience, feed-in-tariffs, and reformation of renewable portfolio 
standards (Malen \& Marcus, Transforming Clean Energy Technologies into Viable Business Opportunities in US States, 2016). Public acceptance of technology also significantly influences the formation of favorable industries. Lettice, Smart, Baruch, \& Johnson (2012) explain how high public acceptance accelerates the diffusion rate of innovation by demonstrating that projects with higher public acceptance are more likely to be funded than other projects with lower public acceptance. Moreover, when large corporations are interested in the technology or project, investors are likely to deploy capital to the project with disruptive technology. Other macroeconomic conditions can also cause an increase or decrease in capital investments in cleanand hard-technologies. (Gaddy, Sivaram, \& O'Sullivan, 2016) demonstrate that turbulent economic conditions following the financial crisis in 2008 caused venture capital to halt investment in the clean technology sector, failing to support many cleantech startups. The conditions of an industry, favorable or otherwise, tend to have a dramatic influence over investors' appetites and confidence. When investors are unable to secure a competitive pathway or capture any "possibility of unfavorable economic conditions," they become reluctant to invest in the technology even when it is commercially ready and economically viable (Fernandez, Stein, \& Lo, 2012).

As a result, critical decisions in the clean- and hard-tech industries are often based on external factors, while relatively less attention is placed by investors and analysts on internal factors, such as a company's management and technological capabilities (Bjornali \& Ellingsen, 2014; Tsoutsos \& Stamboulis, 2005). And yet, 'resilience' has been shown to be a key to building a healthy and robust entrepreneurship ecosystem: (Roundy, Brockman, \& Bradshaw, 2017) defines resilience as "the degree to which an entrepreneurship ecosystem can continuously recover from and adapt to exogenous shocks and endogenous pressures" (p. 101). Entrepreneurs must anticipate disturbances from external and internal factors, , and a resilient entrepreneurship ecosystem refers to a system where entrepreneurs can reduce the time needed to recover from such disruptions and even become stronger after surviving them (Limburg, O'Neill, Costanza, \& Farber, 2002) (Holling, 1986) (Holling \& Gunderson, 2002). Hence, we study which of the other causal conditions that these conditions interact with and how. We postulate that having a favorable industry is not the single, dominant determinant for a successful exit. 


\subsection{Commercial Readiness}

During the tech-to-market process, investors' primary objective is to decrease the time, capital, and cost of their new technology product. By reducing these inputs, the entrepreneurs reduce the technology risks and marketing uncertainty, which is needed for later-stage investors and acquirers to ensure project success. This type of evaluation requires a standardized scale that consistently measures and demonstrates the maturity of technologies and their readiness, often referred to as the technology readiness level (TRL). In evaluating exit potential, investors always seem to rely on TRLs to judge the technology risks. It is widely accepted that a project with a high TRL is likely to exhibit high value and to attract more investment and exit opportunities. However, this research is not simply interested in validating the TRL convention, but, rather, we want to investigate which exit strategies are most effective at different TRLs. As we have seen different exit scenarios at different TRLs, we cannot assume that TRL is a single, dominant factor that determines the investment outcome. However, TRL should interact with other financial and nonfinancial factors to determine an exit pathway. A strategy that works for a highly mature project may not be appropriate for an early-stage project.

For this project, we assess an interviewee's TRL by using the U.S. Department of Energy's (DOE) TRL scale, albeit with simplified intervals. Based on the technology assessment models developed by NASA and the U.S. Department of Defense, the U.S. Department of Energy (2011) introduced a technology readiness assessment guide to assist individuals and teams in their plans to reach a desired TRL. For this assessment, the DOE scale includes a range from 1 (basic principles observed) through 9 (total system used successfully in project operations). For the analysis in this paper, we simplify the scale by reducing it from nine steps to five categories in order to mitigate potential inconsistencies due to different measurement criteria. We aggregated TRL up to 3 into the first category, which includes the earliest phases until proof of concept. Our second category is equivalent to TRL 4 , which represents a technology that is validated at a lab scale. The third category is TRL 5, which indicates the technology is validated and demonstrated in a relevant environment. The fourth category covers TRL 6 and 7 when the prototype is demonstrated in a relevant and actual operational environment. Lastly, the fifth category includes all the periods that go beyond TRL 8 when the technology is fully proven and commercialized. 


\subsection{Visibility to Relevant Investors}

Building strong networks with relevant investors can be one of the essential causal conditions required to increase a company's chance of a successful exit. (Polzin, 2017) shows that the matching process between investors and entrepreneurs involves a two-stage process: the process of entrepreneurs finding investors and investors screening the entrepreneurs. This matching process illustrates the importance of increasing firms' visibility to relevant investors, for established contact coming from the firms' visibility allows the generation of deal flow between investors and entrepreneurs.

We assume that visibility to relevant investors (i.e., geographical adjacency or frequency of interaction) and the process of being visible to investors (e.g., networking, prize competitions, and fellowships) influence strongly a firm's business development and fundraising. Some previous studies demonstrate the close geographical connection between investors and firms and decide to test how geography plays a role in increasing the firms' visibility to relevant investors. (Sorenson \& Stuart, 2005) find that approximately 70 miles is the average distance between the target firm and lead venture capital. Sohl, Van Osnabrugge, \& Robinson (2000) and Wong (2002) highlight how angel investors tend to be geographically close to entrepreneurs to which they provide funding. It is a market convention that entrepreneurs actively use various search channels to be visible to investors. To reduce search costs and increase visibility, entrepreneurs leverage existing search channels such as fairs and conferences, family and friends, existing business relations or more structured incubator programs (Gompers \& Lerner, The venture capital revolution, 2001).

\subsection{Interactions with Actual Investors}

How an entrepreneur builds and maintains a relationship with their investors can also be a critical causal condition affecting exit. The importance of the entrepreneur-investor relationship is underscored by entrepreneurship studies, which suggest strong relationships can bring entrepreneurial success through powerful resource and idea exchange. Huang \& Knight (2017) argue that active entrepreneur-investor interaction can strengthen the relationship by involving two types of signaling behavior: one is interpersonal signaling, where entrepreneurs build emotional connections with the investors by taking a communicative stance, and the other is informational signaling, where entrepreneurs share the quality and progress of their firm with the investors. Lehtonen (2006) exemplifies the importance of contractual relationship, post-investment 
monitoring, and trust and communication in the investor-entrepreneur interaction. In particular, effective communication methods are critical in successful relationship management and business development.

Our hypothesis on interactions is that the frequency of dialogue between entrepreneurs and their investors has an effect on exit performance. We conjecture that this organizational element supports entrepreneurs and investors to align their objectives and approaches. This makes the pathway to exit more efficient, and the probability of a successful exit increases accordingly. Instead of simply quantifying the frequency of these interactions, we consider other aspects: We assess how much forward-looking information they share. For example, many startups are so caught up by raising the initial/next round of funding that they undermine their long-term prospects. Likewise, investors, whose concern is faster exits and higher multiples, often have plans that do not align with startups' plans. When the strategies of investors and entrepreneurs differ widely, the project may confront significant disagreements on exit opportunities and have to pivot. Even if a startup manages to raise the first round of funding, a startup may have to take more time and capital to reach an exit when it takes a pivot to re-align with goals and approaches.

\subsection{Management Experience}

Investors view the management capabilities of a project team as being just as critical as the project's technological capabilities. Both the founder's industry experience and educational background are positively correlated with creating novel technology (Jensen, Lööf, \& Stephan, 2019). Previous studies investigate the correlation between the project team's management capabilities and the probability of project success: Politis (2008) demonstrates the important role of prior startup experience for entrepreneurs' success. Serial entrepreneurs with prior management experience are likely to have further success because more experienced venture capital firms that have higher success rates tend to finance serial entrepreneurs (Gompers, Kovner, Lerner, \& Scharfstein, 2010). Furthermore, prior management experience is a promising element of the firms' successful exit, because prior experiences allow the firm to "orchestrate, manipulate, and leverage the ecosystem to their advantage" (Walsh, 2016).

\subsection{Non-financial support}

An early-stage project needs plenty of financial and business support to succeed. This type of support often comes from universities, national labs, and other philanthropic organizations. They 
provide grants and fellowships, which helps entrepreneurs with their cost of living, benefits, travel, research and development, and business development. Startup incubators and accelerators increasingly provide non-financial support, such as diverse partnership with from university organizations and other external organizations, believing that they can nurture entrepreneurs to succeed in the long run. Weyant, Fu, \& Bowersock (2018) highlight building a comprehensive ecosystem that accommodates perspectives of different players such as entrepreneurs, investors, policymakers and consumers, and In \& Monk (2020) provides specific functions of intermediaries in building such ecosystem. Garfield, Moore, \& Adams (2019) provide a good practice of the proposed approach: they conduct case studies on nine new initiatives supporting early-stage cleantech development of physical systems since 2014, and they discuss the different approaches, focusing on how they differ from traditional business incubators both in their commercialization methodologies and in the combined resources leveraged from founding organizations and partners. For instance, startup accelerators (e.g., GCxN, IN2) that provide resource support, but they also actively connect its cohort to large corporations to gain expert insights and foster connections with future customers. They find that these forms of "non-tangible, non-financial" support helps startups to scale more rapidly.

We test whether this non-financial support influences project success, and we collected indicators of such, including lab access, legal assistance, access to investor network, access to experts and opinion leaders. Meyskens and Carsrud (2013)'s analysis of 50 green-technology ventures demonstrates how partnership diversity with various public, social, educational, and private organizations influences green technology startups' success. They highlight that partnership diversity can bring entrepreneurial success for the firm by facilitating the innovation process, goal alignment, beneficial resource mobilization, and value creation. Doblingner et al. (2013) demonstrate how the firm's close relationships with research organizations can help the firm overcome the constraints of public policy and increase the firm's innovation progress. Therefore, the firm's non-financial affiliation with diverse key players in the ecosystem can generate a significant impact on the firms' development.

\subsection{Straightforward Development Path}

While it often necessary and a critical part in a company's long-term success, "pivoting" from one product, business model or industry to another can carry a negative connotation. Clearly, it rightly signifies that prior attempts to market a technology failed, but the question remains whether it has 
any bearing on future attempts to market the technology in a new way. We thus investigate whether a pivot is associated with the project outcome. Considering the uncertainties of entrepreneurship, it is rare for a startup to come up with one successful business model at the outset (Comberg, Seith, German, \& Velamuri, 2014). Pivot strategies can thus help the firm to leverage its technological innovations by adapting to the demands of the market, which increases a firm's chance of survival (Kirtley \& O'Mahony, 2020). However, because a pivot requires a "reallocation or restructuring of activities, resource, and attention", frequent pivots in the company's pathway to a successful exit can put the startup in an unfavorable position and accelerate startup failure (Meiners, 2018). As this implies, pivots can be an important part of a company's success, but too many pivots can lead to its demise. According to Meiners (2018), pivots were one of the top 20 causes (composing $10 \%$ of total failure) of startup failure, because it led to extensive resource consumption and a decrease in the firm's motivation.

\section{Research Design and Methodology}

We use the fsQCA as the method of causal inference, and follow four main steps, as in Figure 1, adapted from Gasparro \& Walters (2017). First, cases were selected based on research criterion. Second, conditions of possible causal relevance and outcome criteria were defined. Third, the truth table was built with data about each case. Fourth, the fsQCA was run. The subsequent sections describe each of these steps in greater detail.

Figure 1. Summary of the fsQCA approach 


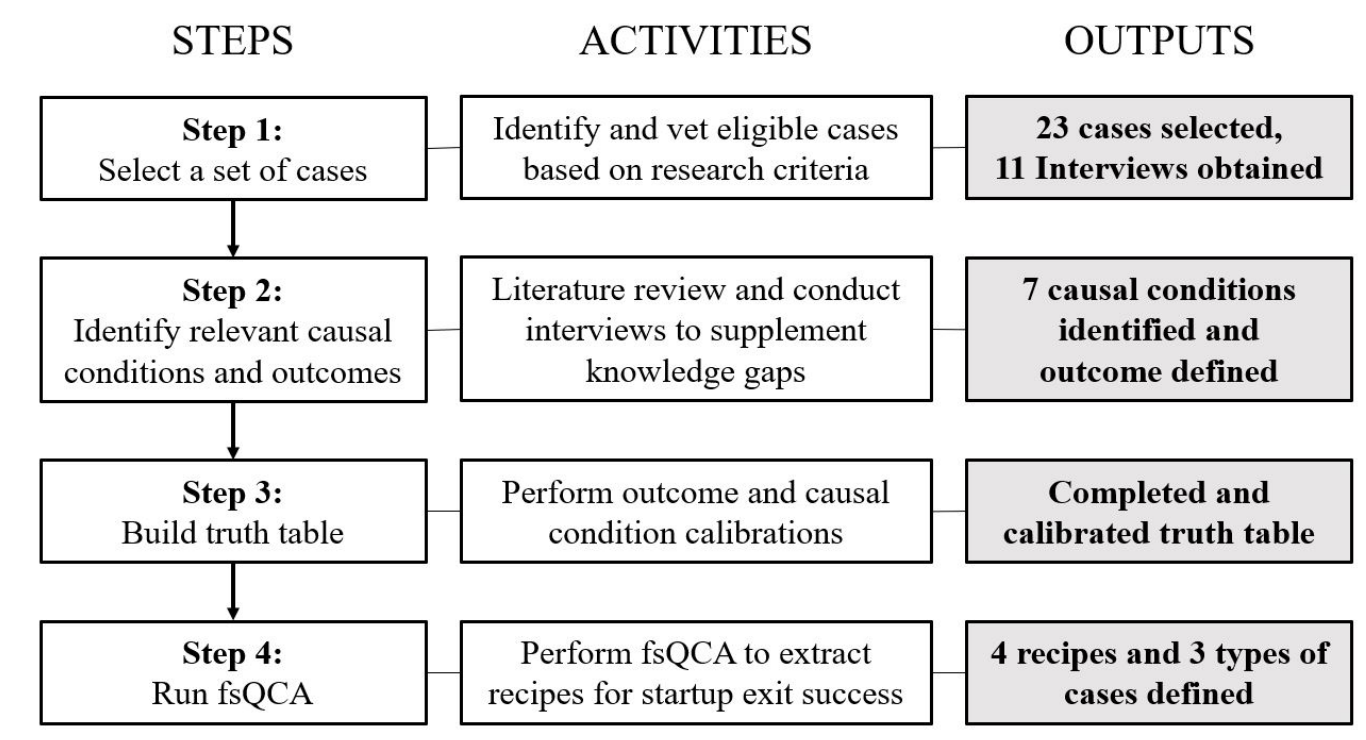

\subsection{Case Selection}

We compiled a comprehensive pool of eligible startups using the PitchBook database and supplemented it with information from semi-structured interviews with industry experts. The following initial search parameters were applied to find companies relevant to the study's geographic area, timeframe, and subject of interest: (1) companies headquartered in the US; (2) companies founded on or after January 1, 2000; and (3) firms that exited through a merger or acquisition between January 1, 2005 and December 31, 2016. Using this homogeneity criteria, 1800 eligible companies were identified. Next, the firm descriptions were screened to distinguish between hardware and software companies. A startup is classified as hardtech if its innovation focused on a physical product or process (e.g. advanced materials, advanced manufacturing, microelectronics, energy generation, energy storage, etc.). Companies that created software to layer on top of hardware are excluded from this definition. Out of the original 1800 companies, 195 were identified to be hardtech companies.

Since fsQCA is a case-oriented approach, a certain depth of knowledge and case expertise is required to draw meaningful conclusions and identify novel recipes for exploration. Cases were therefore further screened based on information sufficiency in the following categories: (1) first financing dates, (2) total dilutive capital raised, (3) exit deal dates, (4) exit amounts, (5) acquirers, and (6) technology readiness level at exit. This yielded 61 companies with enough available information for meaningful analysis, out of which 30 firms were cleantech firms. Cleantech firms were defined as technology-oriented firms that provide a valuable product, service, or process 
while either: (1) using zero or significantly less nonrenewable sources, or (2) generating significantly less waste than conventional offerings (Pernick \& Wilder, 2007; Giudici, Guerini, \& Rossi-Lamastra, 2019). The cleantech industry is wide-ranging and can include recycling, renewable energy, green transportation, green chemistry, and lighting (Cumming, Henriques, \& Sadorsky, 2016; Giudici, Guerini, \& Rossi-Lamastra, 2019). Lastly, case diversity across outcome and causal conditions are necessary to improve confidence in our causal inference claims, as this allows for as many claim counterfactuals as possible. First, companies were screened for outcome diversity within the 30 eligible cases. There were 3 cases with full membership as successful exits and 5 cases with full membership as failed outcomes, when both exit valuation and exit multiple, which is defined as exit value divided by total amount invested, were considered. For the preliminary screening of cases, full membership as successful exit was defined to be cases that exited at a value 5 times or greater than the amount invested, with exit valuation at 50 million or greater. Full membership as unsuccessful exits were defined to be cases with exit value 1 times or less than amount invested, which would mean that investors did not receive positive returns for their investment, and also exit valuation at 5 million or less. Widening the set of cases to include companies that fulfill just the exit multiple criteria for success and failure membership, the total set of cases was increased to 20, with 10 total successful cases and 10 total failed cases. The exit multiple criteria was prioritized over using the raw exit valuation in widening the total set of cases because the exit multiple is a proportional value normalized to the amount that was invested into the company and therefore a more representative indicator of how successful an investment was. These 20 cases represented exit multiples ranging from $0.0026 \mathrm{x}$ (effectively $0 \mathrm{x}$ ) to $31 \mathrm{x}$, and exit amounts that range from 0.1 million to 350 million dollars. The companies were then verified for heterogeneity across causal conditions with the available preliminary data, before interviews were conducted.

Most of the 20 companies had products with high commercial readiness at the time of exit. Within the larger pool of 30 eligible cases, only 1 company was found to have lower technology readiness level (below 5) at time of exit. This case was added to the study pool to improve range of TRL represented, and to provide meaningful comparison for this category, bringing the set to 21 cases. After consultation with industry experts, two other outlier cases considered worthy of study were also added to the case set. The final 23 companies represented a diverse range of industry verticals and technology areas within cleantech, including nuclear, solar, carbon 
nanotubes, aerodynamics, fuel cells, wind, biofuels, batteries, and coatings. However, solar was the most common technology area within this set, and represented 13 out of 23 cases. Our team additionally pre-screened the 23 cases for diversity in incubator or accelerator partnerships, whether the founder had previous startup experience, and whether the company made any pivots. Based on this first rough analysis, our team elected to move all 23 cases forward for a round of indepth interviews.

After the pool of 23 cases were identified, our team began outreach in earnest. Over a period of more than 6 months, our team attempted to reach each company with at least three attempts using industry networks, LinkedIn profiles, and available contact information listed in Pitchbook. A company was recorded as not interested in participating if we did not receive a response after three separate follow-up attempts. During the 6-month period, our team was able to conduct indepth interviews with 11 companies. $^{3}$

These 11 companies were briefly checked for heterogeneity across causal conditions. Of those 11 companies, 6 companies were defined as having a successful exit with a relatively high multiple, while the other 5 either made negative or non-positive multiples (i.e. less than or equal to $1 \mathrm{X}) .5$ out of 11 were developed during a time where their respective industry was considered favorable. Almost all of the companies, 8 out of 11, had a product at exit with high commercial readiness. 4 out of 11 were either headquartered or participated in events such that they were highly visible to potential investors. 8 out of 11 had relatively frequent and in-depth level of contact with their actual investors and alignment of milestones. 5 out of 11 had an experienced entrepreneurial team. 4 out of 11 companies received and used substantial nonfinancial support, either through an official incubator or accelerator program or through effective alliances. Lastly, 6 out of 11 companies had a relatively straightforward development path, of which 3 had no pivots at all. This initial check demonstrated that our set of cases had sufficient diversity that we could move forward

\footnotetext{
${ }^{3}$ The start of interviews coincided with the COVID-19 pandemic, and data collection procedures were adjusted to accommodate the unusual circumstances. Interviewees were approached through a standard invitation email to participate in the study. Interviews were conducted virtually via Zoom video conferencing software to abide by recommended social distancing guidelines. With participant permission and awareness, interviews were recorded to ensure that analysis remained faithful to participant responses. All interviews were kept confidential to the research team. Since the cases in this study are bound by the timeframe of 2005-2016, the research team does not anticipate that the COVID-19 situation impacted research findings. However, because outreach for interviews coincided with the beginning of shelter-in-place protocols and many companies experienced an unusual volume of responsibilities because of the pandemic, it is possible that our overall interviewee response rate was affected.
} 
with a case comparative analysis. A more in-depth case-coding method, described in Section Error! Reference source not found., was then applied to all 11 cases.

\subsection{Semi-Structured Interviews}

\section{Definitions and Indicators}

As discussed in Section 3, we identify seven key thematic causal conditions. Table 2 summarizes the definitions for each causal and outcome condition used in this analysis. Indicators used for conditions and outcomes are also included.

Table 2. Summary of definitions used for this study

\section{Causal Conditions}

(1) Favorable Industry - Contextual factors outside of startup control are amenable and advantageous to the type of innovation being developed.

(2) Commercial Readiness - The startup's technology has been developed to reach a maturity level such that introduction to market is possible.

(3) Visibility to Potential Investors - The firm is positioned such that successful contact between potential investors and the firm is possible.

(4) Interaction with Actual Investors - The nature and frequency of dialogue between the firm and its investors and the degree to which both parties' goals aligned.

(5) Management Experience - Firm leaders have previous experience on building and scaling a startup or relevant industry experience.

(6) Non-financial Support - The firm is affiliated with or uses resources from an outside program or institution.

(7) Straightforward Development Path - The firm has reached exit with minimal pivot activity.

\section{Outcome Condition}

(1) Successful Exit - A cleantech hardware startup was considered a positive investment decision by its investors.

\section{Startup interviews}

Case and theoretical knowledge was supplemented with interviews conducted with key personnel, such as the founders or early-stage employees from each company. Data gathered through interviews focused on company-level information and startup commercialization process. 
The thematic analysis and codebook informed the framework for this study's semistructured interviews and design of key questions. The interview procedure was first piloted with a separate, smaller set of participants to ensure validity and reproducibility of survey instruments. In total, three validation and pilot interviews were conducted. Priority was given to clarity, simplicity, neutrality, and appropriateness to population when designing the interview framework and questions (Cummings and Hulley 2007), and phrasing was stress-tested for ambiguity or hidden assumptions during the pilot phase. Piloting also provided information on approximate length of interviews and allowed the interviewer to gain familiarity with the instrument and practice uniform, conversational delivery. The final list of questions are included in Appendix B.

Interviewing was chosen over self-administered questionnaires to allow for more complete responses and enhanced validity through improved mutual understanding (Cummings and Hulley 2007). The interview format was also important to the exploratory and theory-building purpose of fsQCA, since it allowed for more free-form responses from participants.

In order to maximize reproducibility, fundamental principles of consistency and neutrality were emphasized during the interview process. Best-practice techniques including standardized phrasing of interview questions and probing methods were used (Patton, 1987; Kiernan, Kiernan, \& Goldberg, 2003). Uniform wording was developed for parts of the interview, including: a standard script for consent and research background information provided to the respondent, instructions, question order, and topic transitions. Questions were further kept neutral during presentation; interviewers avoided agreeing or disagreeing with participants and avoided giving opinions or suggesting answers.

\subsection{Coding Schemes and Truth Table Building}

\section{Case Coding Procedure}

In this study, a hybrid process of deductive and inductive thematic analysis was used to interpret the interview data (Fereday \& Muir-Cochrane, 2006), where a theory-driven codebook was first developed a priori (Crabtree \& Miller, 1999) and supplemented with data-driven methods (Boyatzis, 1998) as interview data was compiled. ${ }^{4}$ Codes used for this study mainly consisted of

\footnotetext{
${ }^{4}$ As information on the selected cases were gathered, a process was developed to both manage the textual data gathered from interviews and to code cases within the fsQCA configurational matrix. Systematic coding of text is a critical
} 
index or classification codes, which tag text for retrieval, and measurement codes, which assign quantitative values to text, such as presence or absence of information or frequency (MacQueen, McLellan, Kay, \& Milstein, 1998; Seidel \& Kelle, 1995) (Bernard, 1994) (Bernard \& Ryan, 1998). For both types of code, interview text was meaningfully segmented to include the full elicitation, full response, and all dialog between interviewer and respondent that flowed from the elicitation. Text unitization by "meaning" is a common approach in exploratory research and research that uses a complex, semi-structured interview format, such as in this study (Campbell, Quincy, Osserman, \& Pedersen, 2013). This segmentation technique has the advantage of preserving the context and interview flow on a specific discussion topic (MacQueen, McLellan, Kay, \& Milstein, 1998; Garrison, Cleveland-Innes, Koole, \& Kappelman, 2006). All code development in this study was organized through the QSR NVivo data management program.

Theory-driven codes were developed through three main steps in this study: 1) code generation through literature review and expert guidance; 2) code revision and review in the context of study data; and 3) verification of intercoder agreement and reliability (DeCuir-Gunby, Marshall, \& McCulloch, 2011). Diverse literature review and expertise was necessary during the code generation phase to avoid groupthink and to refine explanations. The research team identified the seven core constructs by first meeting monthly in the first year of study, for approximately 3 hours each time, which amounted to a total of 36 hours in the first year. All that was known about each construct was discussed at length by the research team for an additional 15 hours in the second year to define what each theme represents, what it does not, and how to recognize the theme in

element in qualitative data analysis (Strauss \& Corbin, 1990) (MacQueen, McLellan, Kay, \& Milstein, 1998; Miles \& Huberman, 1984) and useful for demonstrating rigor by forcing researchers to explicate the sound reasoning and choice of methods applied to the research problem (Aroni, et al., 1999; Horsfall, Byrne-Armstrong, \& Higgs, 2001; Koch, 1994; Rice \& Ezzy, 1999). According to DeCuir-Gunby, Marshall, and McCulloch (2011), codes are defined as labels or tags that assign meaning to descriptive information; while MacQueen et al. (1998) further specify that codes form the "building blocks for theoretical development" and function as a "frame or boundary that the analyst constructs in order to systematically map the informational terrain of the text." Creating a structured codebook provides a stable base upon which to build a dynamic analysis of qualitative data (MacQueen, McLellan, Kay, \& Milstein, 1998).

A code generally consists of three main components: (1) code label or name; (2) definition of the code or theme; and (3) a description of how to apply the code or know when the theme occurs (Boyatzis, 1998; Blanchard, 1997). Part 3 can be further broken down into the following components: (1) a descriptive inclusion criteria; (2) exclusion criteria; and (3) specific examples of theme application (MacQueen, McLellan, Kay, \& Milstein, 1998). While there is not a universally agreed upon set of coding procedures (Coffey \& Atkinson, 1996), DeCuir-Gunby, Marshall, and McCulloch (2011) identified three main approaches to code development: 1) theory-driven, from existing concepts; 2) data-driven, emerging from raw data; and 3) structural, from a specific study's research questions and goals. 
natural language. After the research team reached consensus that each code was satisfactorily concise and conceptually meaningful, members of the research team responsible for coding then practiced coding pilot interview data and met to discuss the results to check for inconsistencies and divergent interpretations. A proportion agreement method was used to assess intercoder reliability for each code and across all codes for the pilot data (Campbell, Quincy, Osserman, \& Pedersen, 2013; Morrissey, 1974; Kurasaki, 2000; Miles \& Huberman, 1984). The core themes were then refined and clarified using the "negotiated agreement" approach, where intercoder agreement is improved by code comparison and discussion to reconcile disagreements (Morrissey, 1974; Campbell, Quincy, Osserman, \& Pedersen, 2013; Garrison, Cleveland-Innes, Koole, \& Kappelman, 2006). The theoretically driven codes formed the first iteration and fundamental structure for this study's codebook, upon which later versions were based.

Following data collection, both the interview transcripts and Pitchbook database information were loaded into the NVivo software and the text was rigorously processed to allow data-driven themes to emerge. According to Horsfall, Byrne-Armstrong, and Higgs (2001), rigor in qualitative research includes careful attention to the phenomenon under study; this tenet was adopted in developing data-driven codes by the following four-step process: 1) raw information reduction; 2) new theme identification including subsample themes; 3 ) inductive code generation and (re)assignment; 4) code validation and verification (DeCuir-Gunby, Marshall, \& McCulloch, 2011). First, the raw textual data was reduced into smaller units according to the segmentation strategy previously described. As recommended by Fereday and Muir-Cochrane (2006) and Crabtree and Miller (1999), at this stage of analysis, text classification was guided by but not confined to the preliminary theory-driven codes. As interviews were processed, indicators and sometimes major themes that had not been captured by theory-driven codes were identified using an approach outlined by Boyatzis (1998) and Fereday and Muir (2006) and new inductive, datadriven codes were assigned. Interviews were further compared on the study-level and in subsample groups to reexamine the theory-driven code and evoke new ideas (DeCuir-Gunby, Marshall, \& McCulloch, 2011). Similar to the deductive coding process, the new inductive code definitions were also tested for reliability and checked for robustness against multiple interpretations across coders (Fereday \& Muir-Cochrane, 2006).

While the case coding and theme development process was described as a fairly linear procedure here, in reality it was an iterative process (Fereday \& Muir-Cochrane, 2006; DeCuir- 
Gunby, Marshall, \& McCulloch, 2011). As code themes and inclusion or exclusion criteria were refined, previously coded cases were reexamined and recoded to match the updated understanding of each theme. The final version of the codebook is included in Appendix A.

\section{Translation of Coded Cases to Partial (or Fuzzy-set) Membership Scores and Truth Table Construction}

After cases were provided a raw index score in each of the seven causal conditions using the finalized codebook (Appendix A), the raw index scores were then converted into fuzzy set membership scores in each category. Set membership can be classified as either crisp or fuzzy (Ragin 2009). Crisp membership refers to a binary (either in or out) method of classifying cases, where causal conditions are checked for simple presence/absence. However, for many complex phenomena, there may be a broad range of "in-between cases" (Ragin 2009); for example, a company's entrepreneurial team can range from low to high experience-levels in founding, operating, and scaling a startup; the aggregate level of experience would therefore also fall somewhere on that spectrum. Fuzzy-set theory is the well-established mathematical system used to address partial membership in sets (Ragin 2009; Klir, Clair, and Yuan 1997). Cases in this study were assigned partial membership scores using the calibration methods described in Ragin 2009 and Ragin 2000. Partial membership was considered for all the causal conditions and outcome condition described in this study. The aggregate result after assigning a partial membership score for each case is a truth table, which was inputted into the fsQCA software for case comparative analysis (version 3.1b) (Ragin and Davey 2016). 


\section{Discussion}

Three distinct categories of successful clean hard-tech startups, with four specific "exit recipes", emerged from our analysis. The three categories, summarized in Figure 2 are: (A) robust ecosystem; (B) heavy-lifting team; and (C) external opportunity. Each category name reflects the strong presence of the dominant causal condition within each recipe. Each of the three categories are discussed in further detail in the subsequent sections.

Figure 2. Four fsQCA recipes and three categories of clean hard-tech startup exit

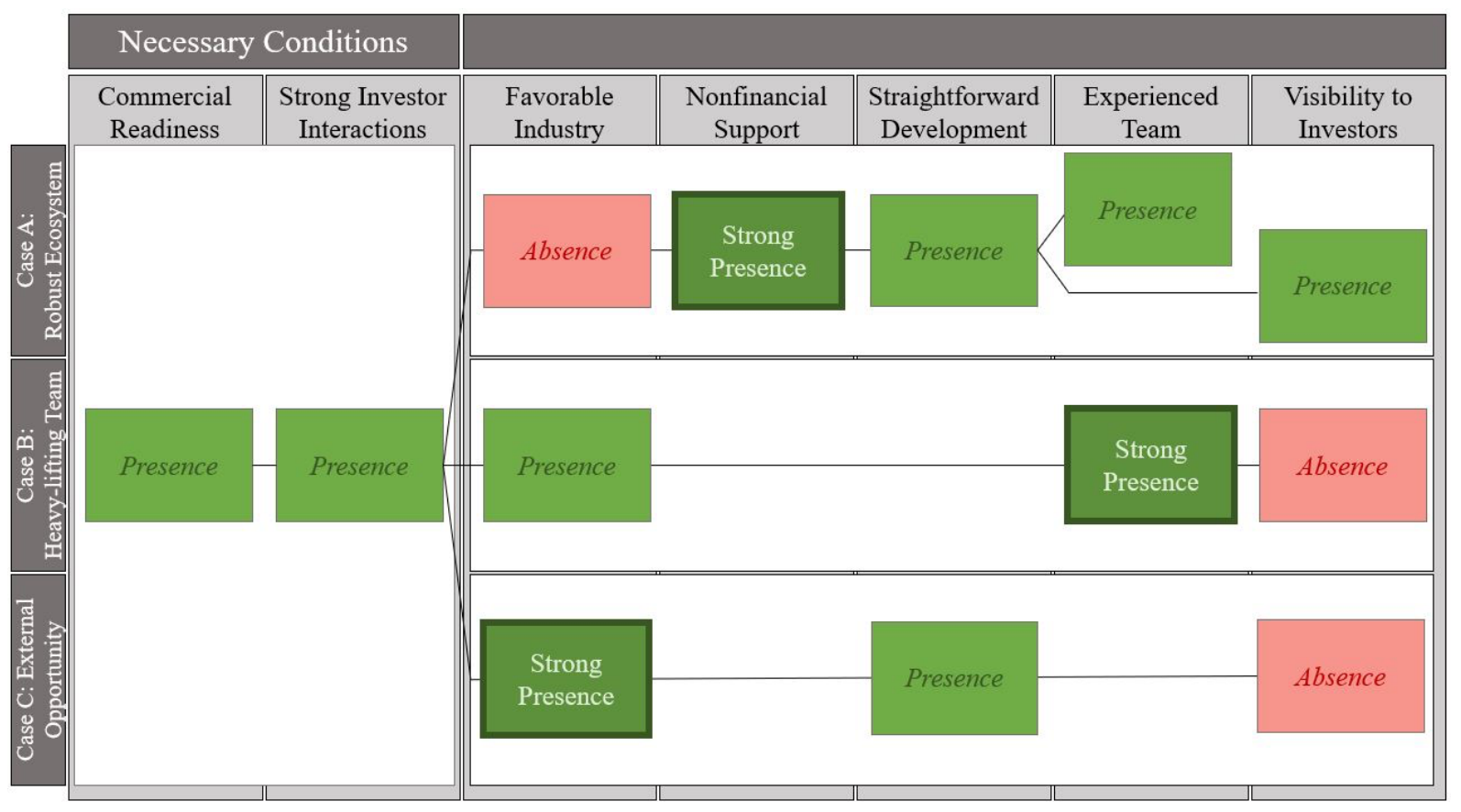

The causal conditions that are present and relevant for each recipe are indicated with a green box, while the negation or absence of conditions are indicated with a red box. We also focus on this negation, as it converses the membership (e.g., a and $\sim$ a) and provides meaningful implications. For instance, the negation of the favorable industry condition in the robust ecosystem does not just imply that the impact of the industry support is insignificant to clean hard-tech startup's exit, but that the change of the industry condition does not influence cases in the robust ecosystem. Conditions that do not appear in a given recipe have no bearing on the outcome of interest (i.e. neither the presence nor absence of this particular condition impacts the given recipe for a successful exit). Of all three types of startups, the "Robust Ecosystem" startup requires the larger 
number of conditions for success (six out of seven) but it is also the only category with multiple recipes.

\section{Necessary Conditions}

Necessary conditions in fsQCA methodology refers to causal conditions that appear in all recipes for an outcome of interest (Ragin 2009). We find that all startups that made a successful exit fulfilled, or had high membership scores in, two causal conditions: commercial readiness and strong investor interactions.

An interpretation of the first necessary condition, commercial readiness, is that, regardless of other factors, the companies that are able to successfully exit have, at minimum, a viable technology or product that is comparatively mature and deployable to commercial markets at the time of exit. This does not mean that investors should only invest when a technology has been validated. Rather, it means that most companies that sought an exit before reaching product maturity did not exit successfully. In most of the cases that were studied, investors joined when the product's commercial readiness was still low, at the basic technology up until proof-of-concept stage. Only one successful case started at a mid-high commercial readiness level (technology validated in relevant environment) when the investors first approached. In other words, our research shows that entrepreneurs and investors alike should be laser focused on getting companies to crystallize a viable pathway to commercial readiness. Clearly this does not mean having a commercially ready product or technology is sufficient, but it is necessary, for a successful exit. For example, rhere was at least one case studied where the company had achieved an advanced commercial readiness level but still exited with a non-positive $(\sim 1 \mathrm{X})$ multiple.

The second necessary condition, strong investor interactions, indicates that successful startups maintained strong connections, with high frequency of communication, with investors. For example, the founder of one company prioritized frequent updates and strong relationships with over a hundred investors, which helped ensure the company had sufficient funding to reach its goals. As one founder reflected, "I was definitely on the phone with [the investors] multiple times per week... and I would say we probably had a meeting with one party or the other almost on a weekly basis." This necessary success condition is intuitive when we consider the significant amount of investment capital the startups need to have any chance of meeting commercial readiness objectives. But beyond simple outreach, our research showed that communications that 
built "trust" were the most important to focus on. And this meant delivering high levels of transparency - the good, the bad and the ugly - to investors on a recurring basis. As one founder told us, "We would send weekly updates... We didn't sugar coat [things]. We told them exactly what was what. And so, I had a high degree of credibility and trust with them, and a lot of them invested two or three times in the course of the company's history." The only pathway for a startup to be successful without this trust-building communication was if a founding team already had a strong relationship with an investor, which we interpreted to mean that trust between the founders and investors was already evident. Again, this does not mean that having strong investor relationships is sufficient for startup success. Rather, our analysis indicates that it is a key part of an exit recipe.

\section{Consistency and Coverage}

The exit recipes - i.e., the combination of necessary conditions for a startup to successfully exit that we developed from our fuzzy-set qualitative methodology= can be further clarified using metrics of 'consistency' and 'coverage' (Ragin 2006). The consistency describes the reliability of a certain recipe in describing the available data; a high consistency score indicates that cases that share a given condition or combination of conditions have high agreement in displaying the outcome of interest (i.e., there exists few or no contradictory evidence for the recipe) (Ragin 2006). The coverage, on the other hand, approximates the relative proportion of successful cases that a recipe describes, relative to the pool of all successful cases studied (Ragin 2006). And when there exists multiple separate pathways that can lead to an outcome of interest, each individual recipe will have lower coverage scores. The overall recipe consistency for this study is 0.908 , and the overall recipe coverage is 0.670 . Individual recipe consistency and coverage scores are also provided for each subsequent section.

\subsection{Robust Ecosystem}

The first type of successful startup leverages a "robust ecosystem." In this category, which includes two different possible recipes, the necessary conditions reflect a highly supportive ecosystem around the founders. In addition to the two necessary conditions listed above, these startups also demonstrated high membership scores in the following conditions: visibility to potential investors, nonfinancial support, and straightforward development path. Interesting, the companies in this 
category often were not associated with a favorable industry, which means success was truly based on internal factors and community.

This category has two component recipes that are the same except for one different necessary condition. One subset had founders without significant experience building companies. But, despite this lack of experience, they were bolstered by high visibility to potential investors, either through event participation or a desirable geographical location. Cases in this first subcategory were often birthed in university settings, out of academic research. The weakness on experience was thus more than made up by exposure to investors - who likely had experience themselves - through university networks and competitions. These companies also seemed to benefit from a "halo effect", but this halo was related to the brand or reputation of a university. For example, when asked why a more expensive office space near a prestigious engineering school was selected over a larger, cheaper space, one founder replied: "I think it was very important... if you're a technology company, like we were, not to lose your visibility to the outside world... so we had, like, kind of the cool, 'sexy' space and everything else. And I think that helped keep us relevant in terms of somebody buying." Winning a university competition was also shown to support the perceived credibility of a startup and a reduced level of risk in the eyes of investors. As a different startup founder put it: "I think it had some cachet to investors to say we have this grant from [a well-known university]... just to say somebody else had looked at this and decided this wasn't a totally kooky idea."

The other recipe in this category presented a very different condition; they lacked investor visibility but, instead, benefited from an experienced team. These experienced founders utilized their established personal networks to both find relevant investors to fund their company and outsource some of their operational needs. Although the second sub-category of companies were not affiliated with universities, the founders did still experience some reputational benefit from allying with an incubator program. As one founder told us, "[The incubator] offered a menu of human resources, recruiting, H.R., finance, accounting, any of the patent attorney and commercial attorney facilities and IT... I think it is a huge benefit versus having to do it yourself. As an entrepreneur, [the operational aspect] is very distracting and not what you want to do first." Akin to the first sub-category of university-grown startups, founders in this second sub-category mention that the reputation of a famous incubator founder increased their perceived credibility in the eyes of potential investors. For entrepreneurs considering this route, it may therefore be 
relevant to not only consider the services provided by an incubator program but also more intangible characteristics such as the program's prestige and reputation.

It is interesting to note that these companies do not require that the industry they are targeting have high favorability to succeed, which implies they are more resilient to external conditions. Indeed, this category of successful cases can be described more generally as having a resilient entrepreneurial ecosystem (Roundy, Brockman, \& Bradshow 2017). Accelerators, incubators, competitions, or fellowships may find their best target pool in this category of startups. their requirement for strong nonfinancial support and potential for success regardless of market favorability may be particularly appealing for a consistent successful output and graduates for these fellowship programs. There is even strong opportunity for incubator and accelerator programs to collaborate in or supersede academic institutions in the role of providing nonfinancial support to the first subcategory of cases. Based on these findings, it may also be added that physical proximity in highly visible areas may be considered a priority for startup builder programs.

\subsection{Heavy-lifting Team}

The second category of successful cases relies on a "heavy-lifting team" to reach a successful exit. In addition to the two necessary conditions, this category of successful cases have high membership scores in: favorable industry and experienced entrepreneurial teams. However, these companies generally lack the traditional metrics (i.e. geographic favorability, participation in events or high-profile competitions, etc.) that would contribute to investor visibility. These companies also appear to succeed especially in times when there is no market favorability.

An interpretation of this category of cases is that the success of these startups is largely internally driven by a highly motivated and experience entrepreneurial team, who is able to deliver a "secret sauce" for success in spite of difficult circumstances. One founder described having one hundred and seven investors, of whom "probably a hundred of them were friends of the family, and the other seven were Wall Street public company investors that invested in bulletin board companies. ... I knew almost all of them personally, and I made sure that they were prioritized and knew what was going on. We didn't sugar coat shit. We told them exactly what was what. And so I had a high degree of credibility and trust with them, and a lot of them invested two or three times in the course of the company's history." Another experienced founder, while discussing how their company exited in 2010 , two years after the last recession, attributed their success to being able to 
accurately predict the next generation of cost reductions for solar energy: "[the incumbent company] independently came to that same conclusion (as our models)... and when they saw we had the first-gen technology, we had some market traction, and we had a very talented team... they wanted us."

Because of the heavy lifting required by the entrepreneurial team for these cases, our team was curious if these founders are likely to burnout from the cleantech space. Among the cases we studied with experienced teams, we found that these entrepreneurs did express feelings of burnout but did not leave the cleantech space. For example, one founder cited burnout as the reason for stepping down from his cleantech company after taking it public; however, he later participated as an early employee in a separate cleantech, hardtech venture. Further research is required to investigate the motivations of serial clean-, hardtech entrepreneurs for continuing to participate in this space despite feelings of burnout and if there are any patterns in the behavior or styles of these founders.

\subsection{External Opportunity}

The final and third category of successful cases are characterized by highly favorable external conditions. To be sure, they had high scores in commercial readiness, alignment with investor interactions, $t$ experienced entrepreneurial teams, and a relatively straightforward development path, but the industry favorability seemed to be the differentiator here. Out of all three categories, these companies were not successful because of founders or incubators. Instead, they made the most of some external phenomenon. For example, one successful company in this category gained large traction and application of their cleantech due to the 2011 Fukushima Daiichi nuclear disaster. While the goal is to foster entrepreneurial activity sustainably and apart from the occurrence of environmental disasters, our findings do support that responsive entrepreneurs can benefit by framing their commercially ready technology using salient current events.

Certain crises can catalyze resource reallocations, and that's what we saw in this category. For example, the current COVID 19 crisis is likely to unlock resources for a variety of new projects, and some smart companies will align themselves with these resources. Similarly, a change in President or policy agenda due to an election can be a trigger for companies to launch successfully, as policy priorities shift from one industry to another. Indeed, this ties neatly into the favorable industry component, which is also a necessary condition. It may seem odd to suggest that a 
company building technology products with a 10- to 20- year horizon might need to time the markets to be successful, but that's precisely what our evidence seems to suggest. An industry's favorability rises and falls as a result of external events (opportunities). And if the company has a viable technology, a strong team with trust-based relationships with investors, they can capitalize on that event and exit successfully. To be sure, further research is required to investigate if favorable market conditions can cause an artificially high exit valuation for a company due to flocking of investors, and whether these companies have continued to succeed after supportive policies have reached their sunset dates.

\section{Conclusion}

We undertook this project and wrote this paper to help clean- and hard-tech entrepreneurs and investors understand how to build successful clean- and hard-tech companies. Through a detailed review of the literature, we identified seven key causal conditions that could be strongly associated with successful clean- and hard-tech startups. These seven conditions were further clarified and studied through semi-structured interviews with founders of companies in these industries. Next, using fsQCA, we formed combinations of multiple causal factors that we found to formulate a startup's strategy to successfully exit. We called these combinations of causal factors "exit recipes", and our hope is they serve a series of useful purposes.

First, by providing recipes of successful pathways to "exit", this paper has helped fill prior gaps in the literature that failed to investigate internal and external, processes and ecosystems, related to startup success. This will help academic researchers continue the important work to understand how companies can successfully deliver clean- and hard-technologies to market.

Second, and perhaps more importantly, we learned a great deal about the challenges and requirements facing entrepreneurs in these industries. We learned that all successful companies had a pathway to commercial readiness and trust-based relationships, driven by transparent or deep prior relationships, with their investors. We also learned that companies in each category of successful case had distinctive characteristics that were needed for success, such as the interaction with non-financial support (in our robust ecosystem case), experienced team (in our heavy-lifting team case), and favorable industry (in our external opportunity case) amplifies a startup's success rate. 
Finally, we learned that no single factor can deliver a successful exit. While prior research tended to focus in depth on single factors, our findings demonstrates that these factors need to be considered in combination.

In sum, these three contributions we hope will help to bring more understanding and certainty to the path facing founders and investors targeting the clean-and hard-tech industries. Our aspiration in doing this project is that with these recipes, more founders and investors will be willing to embark on this incredibly important journey to facilitate a much-needed transition to a clean-energy world. 


\section{Bibliography}

Anderson, P., \& Tushman, M. (2001). Organizational environments and industry exit: The effects of uncertainty, munificence and complexity. Industrial and Corporate Change, 10(3), 675711.

Aroni, R., Goeman, D., Stewart, K., Sawyer, S., Abramson, M., \& Thien, F. (1999). Concepts of rigour: When methodological, clinical and ethical interests interact. the First $A Q R$ Conference. Melbourne, Australia.

Austin, D. H. (1993). An event-study approach to measuring innovative output: The case of biotechnology. The American economic review, 83(2), 253-258.

Austin, D. H. (1993). An event-study approach to measuring innovative output: The case of biotechnology. The American economic review, 83(2), 253-258.

Bürer, M. J., \& Wüstenhagen, R. (2009). Which renewable energy policy is a venture capitalist's best friend? Empirical evidence from a survey of international cleantech investors. Energy policy, 37(12), , 37(12), 4997-5006.

Bandera, C., \& Thomas, E. (2019). To Pivot or Not To Pivot: On the Relationship between Pivots and Revenue among Startups. 52nd Hawaii International Conference on System Sciences. Honolulu, USA.

Bates, T. (2005). Analysis of young, small firms that have closed: Delineating successful from unsuccessful closures. Journal of Business Venturing, 20(3), 343-358.

Baum, J. A., \& Oliver, C. (1991). Institutional linkages and organizational mortality. Administrative science quarterly, 187-218.

Baum, J. A., \& Silverman, B. S. (2004). Picking winners or building them? Alliance, intellectual, and human capital as selection criteria in venture financing and performance of biotechnology startups. Journal of Business Venturing, 19(3), 411-436.

Baum, J. A., Calabrese, T., \& Silverman, B. S. (2000). Don't go it alone: Alliance network composition and startups' performance in Canadian biotechnology. Strategic Management Journal, 21(3), 267-294.

Baumgartner, M., \& Thiem, A. (2017). Often Trusted but Never (Properly) Tested: Evaluating Qualitative Comparative Analysis. Sociological Methods \& Research, 49(2), 279-311.

Benková, E., Gallo, P., Balogová, B., \& Nemec, J. (2020). Factors Affecting the Use of Balanced Scorecard in Measuring Company Performance. Sustainability, 12(3), 1178.

Berg-Schlosser, D., De Meur, G., Rihoux, B., \& Ragin, C. C. (2009). Qualitative Comparative Analysis (QCA) as an Approach. In B. Rihoux, \& C. C. Ragin, Configurational Comparative Methods: Qualitative Comparative Analysis (QCA) and Related Techniques (p. 18). 
Bernard, H. R. (1994). Research Methods in Anthropology: Qualitative and Quantitative Approaches. AltaMira Press.

Bernard, H. R., \& Ryan, G. W. (1998). Qualitative and quantitative methods of text analysis. In Handbook of research methods in cultural anthropology (pp. 595-646).

Berrone, P., Fosfuri, A., Gelabert, L., \& Gomez-Mejia, L. R. (2013). Necessity as the mother of 'green' inventions: Institutional pressures and environmental innovations. Strategic Management Journal, 34(8), 891-909.

Betram, T. A., Tentoff, E., Johnson, P. C., Tawil, B., Van Dyke, M., \& Hellman, K. B. (2012). Hurdles in tissue engineering/regenerative medicine product commercialization: a pilot survey of governmental funding agencies and the financial industry. Tissue Engineering Part A, 18(21-22), 2187-2194.

Bjornali, E. S., \& Ellingsen, A. (2014). Factors Affecting the Development of Clean-tech StartUps: A Literature Review. Energy Procedia, 58, 43-50.

Blanchard, L. (1997). How Do You Define Community? Perspectives of Community Members. American Anthropological Association Annual Meeting.

Bonvillian, W. B., \& Weiss, C. (2015). Technological Innovation in Legacy Sectors. Oxford University Press.

Bose, S., Gao, F., Moshkin, J., Patel, A., \& Laipple, A. (2018, April 30). Collaborative Ecosystems in Sustainable Finance: Harnessing the Wisdom of Crowds. New York, NY, USA: Earth Institute, Columbia University.

Bose, S., Gao, F., Moshkin, J., Patel, A., \& Laipple, A. (2018). Collaborative Ecosystems in Sustainable Finance: Harnessing the Wisdom of Crowds. New York, NY, USA: Earth Institute, Columbia University.

Boudet, H. S., Jayasundera, D. C., \& Davis, J. (2011). Drivers of conflict in developing country infrastructure projects: experience from the water and pipeline sectors. Journal of Construction Engineering and Management, 137(7), 498-511.

Boyatzis, R. (1998). Transforming qualitative information: Thematic analysis and code development. Thousand Oaks, USA: Sage Publications.

Boyer, T., \& Blazy, R. (2014). Born to be alive? The survival of innovative and non-innovative French micro-start-ups. Small Business Economics, 42(4), 669-683.

Burton, M. D., Sørensen, J. B., \& Beckman, C. M. (2001). Coming from good stock: Career histories and new venture formation.

Campbell, J. L., Quincy, C., Osserman, J., \& Pedersen, O. K. (2013). Coding in-depth semistructured interviews: Problems of unitization and intercoder reliability and agreement. Sociological Methods \& Research, 42(3), 294-320. 
Carree, M. A., Verheul, I., \& Santarelli, E. (2011). Sectoral patterns of firm exit in Italian provinces. Journal of Evolutionary Economics, 21(3), 499-517.

Carter, N. M., Williams, M., \& Reynolds, P. D. (1997). Discontinuance among new firms in retail: The influence of initial resources, strategy, and gender. Journal of Business Venturing, $12(2), 125-145$.

Chamanski, A., \& Waagø, S. J. (2001). Organizational performance of technology-based firmsthe role of technology and business strategies. Enterprise and innovation management Studies, 2(3), 205-223.

chnological Innovation in Legacy Sectors. (n.d.).

Coffey, A. J., \& Atkinson, P. A. (1996). Making sense of qualitative data: Complementary research strategies. Sage Publications.

Comberg, C., Seith, F., German, A., \& Velamuri, V. K. (2014). Pivots in startups: Factors influencing business model innovation in startups. The International Society for Professional Innovation Management (ISPIM). Dublin, Ireland: Innovation for Sustainable Economy \& Society.

Crabtree, B. F., \& Miller, W. L. (1999). Doing qualitative research. Thousand Oaks, USA: Sage Publications.

Crilly, N. (2018). 'Fixation' and 'the pivot': balancing persistence with flexibility in design and entrepreneurship. International Journal of Design Creativity and Innovation, 6(1-2), 5265.

Criscuolo, C., \& Menon, C. (2015). Environmental policies and risk finance in the green sector: Cross-country evidence. Energy Policy, 83, 38-56.

Cumming, D., Henriques, I., \& Sadorsky, P. (2016). 'Cleantech' venture capital around the world. International Review of Financial Analysis, 44(March), 86-97.

Dakin, K. (2014). Proactive Angel Investing. Technology Transfer and Entrepreneurship, 1(2), 86-91.

DeCuir-Gunby, J. T., Marshall, P. L., \& McCulloch, A. W. (2011). Developing and using a codebook for the analysis of interview data: An example from a professional development research project. Field Methods, 23(2), 136-155.

Del Sarto, N., Di Minin, A., Ferrigno, G., \& Piccaluga, A. (2019). Born global and well educated: start-up survival through fuzzy set analysis. Small Business Economics, 1-19.

Demirel, P., \& Parris, S. (2015). Access to finance for innovators in the UK's environmental sector. Technology Analysis \& Strategic Management, 27(7), 782-808. 
Demirel, P., Li, Q. C., Rentocchini, F., \& Tamvada, J. P. (2019). Born to be green: new insights into the economics and management of green entrepreneurship. Small Business Economics, 52(4), 759-771.

DeTienne, D. R. (2010). Entrepreneurial exit as a critical component of the entrepreneurial process: Theoretical development. Journal of Business Venturing, 25(2), 203-215.

DifferentFunds, Inc. (2020). DeepTech Investing Report. DifferentFunds, Inc.

Doblinger, C., Dowling, M., \& Helm, R. (2013). Does Public Policy Stimulate Firm Entrepreneurial Behavior and Innovative Activities? Academy of Management Annual Meeting Proceedings. 1. Academy of Management.

Fereday, J., \& Muir-Cochrane, E. (2006). Demonstrating rigor using thematic analysis: A hybrid approach of inductive and deductive coding and theme development. International journal of qualitative methods, 5(1), 80-92.

Fernandez, J.-M., Stein, R. M., \& Lo, A. W. (2012). Commercializing biomedical research through securitization techniques. Nature biotechnology, 30(10), 964-975.

Fiss, P. C. (2007). A set-theoretic approach to organizational configurations. Academy of management review, 32(4), 1180-1198.

Florida, R., \& Smith, Jr., D. F. (1992). Venture capital's role in economic development: An empirical analysis. Sources of metropolitan growth, 183-209.

Florida, R., \& Smith, Jr., D. F. (1993). Venture capital formation, investment, and regional industrialization. Annals of the Association of American Geographers, 83(3), 434-451.

Gaddy, B., Sivaram, V., \& O'Sullivan, F. (2016). enture Capital and Cleantech: The Wrong Model for Clean Energy Innovation. MIT Energy Initiative Working Paper.

Gaddy, D. B., Sivaram, D. V., \& O'Sullivan, D. F. (2016). Venture Capital and Cleantech: The Wrong Model for Clean Energy Innovation. MIT Energy Initiative.

Garfield, D. J., Moore, K. E., \& Adams, R. (2019). New Approaches to Energy Hardware Innovation and Incubation. The Joint Institute for Strategic Energy Analysis White Paper (NREL/MP-6A65-73438).

Garrison, D. R., Cleveland-Innes, M., Koole, M., \& Kappelman, J. (2006). Revisiting methodological issues in transcript analysis: Negotiated coding and reliability. The Internet and Higher Education, 9(1), 1-8.

Gasparro, K. E., \& Walters, J. P. (2017). Revealing causal pathways to sustainable water service delivery using fsQCA. Journal of Water, Sanitation and Hygiene for Development, 7(4).

Giudici, G., Guerini, M., \& Rossi-Lamastra, C. (2019). The creation of cleantech startups at the local level: the role of knowledge availability and environmental awareness. Small Business Economics, 52(4), 815-830. 
Goldman, D., Fennell, T., Miller, D., Davis, C., \& White, L. (2017). CLEAN TECH 3.0: Venture Capital inVesting in early stage Clean energy a Changing investment Climate. Ceres.

Gompers, P., \& Lerner, J. (2001). The venture capital revolution. Journal of economic perspectives, 15(2), 145-168.

Gompers, P., Kovner, A., Lerner, J., \& Scharfstein, D. (2010). (2010). Performance persistence in entrepreneurship. Journal of financial economics, 96(1), 18-32.

Gorbolskaya, U. (2015). Probability of Going Public for Cleantech Startups Based on Fundraising Milestones. Master's thesis. Harvard Extension School.

Gulati, R., \& Higgins, M. C. (2003). Which ties matter when? The contingent effects of interorganizational partnerships on IPO success. Strategic Management Journal, 24(2), $127-144$.

Hörisch, J., Kollat, J., \& Brieger, S. A. (2017). What influences environmental entrepreneurship? A multilevel analysis of the determinants of entrepreneurs' environmental orientation. Small Business Economics, 48(1), 47-69.

Hall, B. H., \& Lerner, J. (2010). The financing of R\&D and innovation. In B. H. Hall, \& N. Rosenberg, Handbook of the Economics of Innovation (pp. 609-639). North-Holland.

Hasenauer, R., Gschöpf, A., \& Weber, C. (2016). Technology readiness, market readiness and the triple bottom line: An empirical analysis of innovating startups in an incubator. Portland International Conference on Management of Engineering and Technology (PICMET), (pp. 1387-1428). Honolulu.

Heap, D., Pless, J., \& Aieta, N. (2013). Clean Energy Finance: Challenges and Opportunities of Early-Stage Energy Investing. National Renewable Energy Laboratory (NREL) Industry Growth Forum. Golden, CO (United States).: National Renewable Energy Lab (NREL).

Holling, C. (1986). The resilience of terrestrial ecosystems; local surprise and global change. In W. Clark, \& R. Munn, Sustainable Development of the Biosphere (pp. 292-317). Cambridge, U.K.: Cambridge University Press.

Holling, C., \& Gunderson, L. (2002). Resilience and adaptive cycles. . In L. Gunderson, \& C. Holling, Panarchy: Understanding Transformations in Human and Natural Systems (pp. 25-62). Washington, DC: Island Press.

Hoppmann, J., Peters, M., Schneider, M., \& Hoffmann, V. (2013). The two faces of market support-How deployment policies affect technological exploration and exploitation in the solar photovoltaic industry. Research Policy, 42(4), 989-1003.

Horsfall, D., Byrne-Armstrong, H., \& Higgs, J. (2001). Researching critical moments. In H. ByrneArmstrong, J. Higgs, \& D. Horsfall, Critical moments in qualitative research (pp. 3-16). Oxford, UK: Butterworth Heinemann. 
Huang, L., \& Knight, A. P. (2017). Resources and relationships in entrepreneurship: An exchange theory of the development and effects of the entrepreneur-investor relationship. Academy of Management Review, 42(1), 80-102.

In, S. Y., \& Monk, A. (2020). Financing Energy Innovation: The Need for New Intermediaries in Clean Energy. Stanford Global Projects Center Working Paper.

Jaffe, A. B. (2012). Technology policy and climate change. Climate Change Economics, 3(4).

Jensen, F., Lööf, H., \& Stephan, A. (2019). New ventures in Cleantech: Opportunities, capabilities and innovation outcomes. Business Strategy and the Environment, 29(3).

Jin, Z. (2011). Global technological change: From hard technology to soft technology. Chicago, USA: Intellect Books.

Jordan, E., Gross, M. E., Javernick-Will, A. N., \& Garvin, M. J. (2011). Use and misuse of qualitative comparative analysis. Construction Management and Economics, 29(11), 11591173.

Kaplan, R. S. (2009). Conceptual foundations of the balanced scorecard. Handbooks of management accounting research, 3, 1253-1269.

Kelly, P., \& Hay, M. (2003). Business angel contracts: the influence of context. Venture Capital, $5(4), 287-312$.

Kenney, M. (1988). Biotechnology: The university-industry complex. Yale University Press.

Kiernan, M., Kiernan, N., \& Goldberg, J. (2003). Using Standard Phrases in Qualitative Interviews. Tipsheet \#69. University Park, PA, USA: Penn State Cooperative Extension.

Kirtley, J., \& O'Mahony, S. (2020). What is a pivot? Explaining when and how entrepreneurial firms decide to make strategic change and pivot. Strategic Management Journal, 1-34.

Knight, E. R. (2010). The economic geography of clean tech venture capital. Avaiable at SSRN 1588806.

Knox-Hayes, J. (2010). Creating the carbon market institution: analysis of the organizations and relationships that build the market. Competition \& Change, 14(3-4), 176-202.

Koch, T. (1994). Establishing rigour in qualitative research: The decision trail. Journal of Advanced Nursing, 19, 976-986.

Kurasaki, K. S. (2000). Intercoder reliability for validating conclusions drawn from open-ended interview data. Field Methods, 12(3), 179-194.

Leatherbee, M., \& Katila, R. (2017). Stay the course or pivot? Antecedents of cognitive refinements of business models in young firms. Academy of Management Annual Meeting Proceedings. 
Lehtonen, O. (2006). Power between entrepreneurs and investors: A case study. Journal of Entrepreneurial Finance, 11(1), 51-75.

Lerner, J. (1994). Venture capitalists and the decision to go public. Journal of financial Economics, 35(3), 293-316.

Lettice, F., Smart, P., Baruch, Y., \& Johnson, M. (2012). Navigating the impact-innovation double hurdle: The case of a climate change research fund. Research Policy, 41(6), 1048-1057.

Limburg, K., O'Neill, R., Costanza, .., \& Farber, S. (2002). Complex systems and valuation. Ecological Economics, 41(3), 409-420.

MacQueen, K. M., McLellan, E., Kay, K., \& Milstein, B. (1998). Codebook development for teambased qualitative analysis. Culrurul Anthropology Methods , 10(2), 31-36.

Malen, J., \& Marcus, A. A. (2016). Transforming Clean Energy Technologies into Viable Business Opportunities in US States. Academy of Management Proceedings.

Malen, J., \& Marcus, A. A. (2017). Promoting clean energy technology entrepreneurship: The role of external context. Energy Policy, 102, 7-15.

Marino, K. E., \& De Noble, A. F. (1997). Growth and early returns in technology-based manufacturing ventures. The Journal of High Technology Management Research, 8(2), 225-242.

Mason, C., \& Stark, M. (2004). What do investors look for in a business plan? A comparison of the investment criteria of bankers, venture capitalists and business angels. International small business journal, 22(3), 227-248.

Maurer, I., \& Ebers, M. (2006). Dynamics of social capital and their performance implications: Lessons from biotechnology start-ups. Administrative Science Quarterly, 51(2), 262-292.

Mazzucato, M., \& Semieniuk, G. (2018). Financing Renewable Energy: Who Is Financing What and Why It Matters. Technological Forecasting and Social Change, 127, 8-22.

McGee, J. E., Dowling, M. J., \& Megginson, W. L. (1995). Cooperative strategy and new venture performance: The role of business strategy and management experience. Strategic management journal, 16(7), 565-580.

Meiners, F. L. (2018). A dark side of pivoting?: the effect on employee motivation and commitment. dissertation. Universidade Católica Portuguesa.

Meyskens, M., \& Carsrud, A. L. (2013). Nascent green-technology ventures: a study assessing the role of partnership diversity in firm success. Small Business Economics, 40(3), 739-759.

Miles, M. B., \& Huberman, A. M. (1984). Qualitative data analysis: A sourcebook of new methods. In Qualitative data analysis: a sourcebook of new methods. Sage publications.

Monk, A., Kearney, S., Seiger, A., \& Donnelley, E. (2015). Energizing The US Resource Innovation Ecosystem: The Case for an Aligned Intermediary to Accelerate GHG 
Emissions Reduction. Stanford Global Projects Center \& Stanford Steyer-Taylor Center for Energy Policy and Finance Working Paper.

Morrissey, E. R. (1974). Sources of error in the coding of questionnaire data. Sociological Methods \& Research, 3(2), 209-232.

Nemet, G. (2009). Demand-pull, technology-push, and government-led incentives for nonincremental technical change. Research Policy, 38(5), 700-709.

Parastuty, Z., Breienecker, R. J., Scharz, E. J., \& Harms, R. (2016). Exploring the Reasons and Ways to Exit: The Entrepreneur Perspective. Springer.

Patton, M. Q. (1987). How to use qualitative methods in evaluation. Newbury Park, USA: Sage Publications.

Pernick, R., \& Wilder, C. (2007). The clean tech revolution. HarperCollins e-books.

Petkova, A. P., Wadhwa, A., Yao, X., \& Jain, S. (2014). Reputation and decision making under ambiguity: A study of US venture capital firms' investments in the emerging clean energy sector. Academy of Management Journal, 57(2), , 57(2), 422-448.

Politis, D. (2008). Does prior start-up experience matter for entrepreneurs' learning? Journal of Small Business and Enterprise Development, 15(3), 472-489.

Polzin, F. (2017). Mobilizing private finance for low-carbon innovation - A systematic review of barriers and solutions. Area Development and Policy, 77, 525-535.

Porter, M. E. (1992). Capital Disadvantage: America's Falling Capital Investment System. Harvard Business Review(September-October Issue), 65-82.

Powell, W. W., Koput, K. W., Bowie, J. I., \& Smith-Doerr, L. (2002). The spatial clustering of science and capital: Accounting for biotech firm-venture capital relationships. Regional Studies, 36(3), 291-305.

Ragin, C. C. (1987). The comparative method. Univ of California Press.

Rahmany, M. B., Tawil, B. J., Hellman,, K. B., Johnson, P. C., Van Dyke, M., \& Bertram, T. (2013). Bench to business: a framework to assess technology readiness. Tissue Engineering Part A, 19(21-22), 2314-2317.

Rai, V., Funkhouser, E., Udwin, T., \& Livingston, D. (2015). Venture capital in clean energy innovation finance: insights from the US market during 2005-2014. Available at SSRN 2676216 .

Rice, P., \& Ezzy, D. (1999). Qualitative research methods: A health focus. Melbourne: Oxford University Press.

Rosenthal, J. (2017, 1 19). How to Build a Hard Tech Startup . WIRED. 
Roundy, P. T., Brockman, B. K., \& Bradshaw, M. (2017). The resilience of entrepreneurial ecosystems. Journal of Business Venturing Insights, 8, 99-104.

Saxenian, A., \& Sabel, C. (2008). Roepke lecture in economic geography venture capital in the "periphery": the new argonauts, global search, and local institution building. Economic Geography, 84(4), 379-394.

Seidel, J., \& Kelle, U. (1995). Different Functions of Coding in the Analysis of Textual Data. . In U. Kelle, Computer-Aided Qualitative Data Analysis: Theory, Methods, and Practice (pp. 52-61). Sage Publications.

Silverman, B. S., \& Baum, J. A. (2002). Alliance-based competitive dynamics. Academy of management journal, 45(4), 791-806.

Sohl, J., Van Osnabrugge, M., \& Robinson, R. J. (2000). Models of angel investing: Portals to the early stage market. Frontiers of entrepreneurship research.

Song, M., Podoynitsyna, K., Van Der Bij, H., \& Halman, J. (2008). Success factors in new ventures: A meta-analysis. Journal of product innovation management, 25(1), 7-27.

Sorenson, O., \& Stuart, T. E. (2005). The evolution of venture capital investment networks. Federal Reserve Bank of Atlanta.

Strauss, A., \& Corbin, J. (1990). Basics of qualitative research. Sage publications. Sage publications.

Stuart, T. E., Hoang, H., \& Hybels, R. C. (1999). Interorganizational endorsements and the performance of entrepreneurial ventures. Administrative science quarterly, 44(2), 315-349.

Thomas, J., O’Mara-Eves, A., \& Brunton, G. (2014). Using qualitative comparative analysis (QCA) in systematic reviews of complex interventions: a worked example. Systematic reviews, $3(1), 67$.

Tsoutsos, T. D., \& Stamboulis, Y. A. (2005). The sustainable diffusion of renewable energy technologies as an example of an innovation-focused policy. Technovation, 25(7), 753-761.

U.S. Department of Energy. (2011). Technology Readiness Assessment Guide. Washington, D.C.: U.S. Department of Energy.

Umesh, U. N., Jessup, L., \& Huynh, M. Q. (2007). Current Issues Faced by Technology Entrepreneurs. Communications of the ACM, 50(10), 60-66.

Vuong, Q. H., \& Napier, N. K. (2014). Resource curse or destructive creation in transition: evidence from Vietnam's corporate sector. Management Research Review, 37(7), 642-657.

Vuong, Q. H., Do, T. H., \& Vuong, T. T. (2016). Resources, experience, and perseverance in entrepreneurs' perceived likelihood of success in an emerging economy. Journal of Innovation and Entrepreneurship, 5(18).

Walsh, A. (2016). Entrepreneurship and Firm Performance. Nova Science Publishers, Inc. 
Wang, G., Li, L., \& Jiang, X. (2019). Entrepreneurial Business Ties and New Venture Growth: The Mediating Role of Resource Acquiring, Bundling and Leveraging. Sustainability, $11(1), 244$.

Wennberg, K. (2011). Exit. In L.-P. Dana, World encyclopedia of entrepreneurship (pp. 170-177). Cheltenham, UK: Edward Elgar.

Weyant, J. P. (2011). Accelerating the development and diffusion of new energy technologies: Beyond the "valley of death". Energy Economics, 33(4), 674-682.

Weyant, J., Fu, E., \& Bowersock, J. (2018). Renewed Energy: Insights for Clean Energy’s Future. Kauffman Fellows Press.

Wong, A. Y. (2002). Angel finance: the other venture capital. Available at SSRN 941228.

Yang, C., Bossink, B., \& Peverelli, P. (2017). High-tech start-up firm survival originating from a combined use of internal resources. Small Business Economics, 49(4), 799-824.

Zacharakis, A. L., \& Meyer, G. D. (2000). The potential of actuarial decision models: can they improve the venture capital investment decision? Journal of Business venturing, 15(4), 323-346.

Zahra, S. A., \& Bogner, W. C. (2000). Technology strategy and software new ventures' performance: Exploring the moderating effect of the competitive environment. Journal of business venturing, 15(2), 135-173.

Zhong, H., Liu, C., Zhong, J., \& Xiong, H. (2018). Which startup to invest in: a personalized portfolio strategy. Annals of Operations Research, 263(1-2), 339-360. 


\section{Appendix A. Indicators and Codebook for Causal Conditions}

\section{(1) Favorable Industry}

\section{Indicators:}

a. High rate of consumer or market adoption for the firm's type of core technology during study period

b. Whether there was favorable industry policy during study period of interest

c. Whether large companies were buying firm's type of core technology

d. Whether the firm's investors had prior experience with cleantech, or the firm's core technology

\section{Scoring system:}

Index score out of 8:

- Consumer or market adoption (3 points possible: 0 for none, 1-3 for low-high)

- Favorable policy (3 points possible: 0 for none, 1-3 for low-high)

- $\quad$ Buyers exist (1 point possible)

- Investor familiarity (1 point possible)

\section{(2) Commercial Readiness}

\section{Indicators:}

a. Firm's technology readiness level (TRL) when investors were first approached

b. Firm's TRL at time of exit

c. Difference between the firm's TRLs at the following milestones:

i.Investors were first approached 
ii.First investment was made
iii.The firm made its exit (if any)

\section{Scoring system:}

Index score out of 2:

- TRL at exit ( $100 \%$ is category 5 , according to questionnaire category)

- Calibrate TRL relative to other successful cases

(3) Visibility to Relevant Investors

\section{Indicators:}

a. Whether the firm is geographically located in a city categorized with high concentration of potential investors

b. Number of networking events, competitions, and fellowships that the firm participated in

c. Whether the company won any competitions (if any)

\section{Scoring system:}

Index score out of 8:

- Geographic favorability (3 points possible: 0 for none, 1-3 for low-high)

- Number of events (3 points possible: 0 for none, 1-3 for low-high)

- Competition wins (2 point possible: 0 for none, 2 means 2 or more)

(4) Interaction with Actual Investors 


\section{Indicators:}

a. Presence or absence a prior relationship between the firm's entrepreneurial team and its investors, including personal, from industry, or previous ventures

b. Self-reported frequency of interaction with investors, both formal and informal, including meetings, group network events, and conversations leading to the drafting and negotiation by lawyers on both sides that document the investment

c. Self-reported timescale used in firm-investor discussions

d. Whether the firm's description fit a specific investment criteria for the investor (i.e. cleantech, type of core technology, etc.)

\section{Scoring system:}

Index score out of 9:

- Prior relationship (2 point possible, 1 for personal, 1 for prior collaboration)

- Frequency of discussion (3 points possible: 0 for none, 1-3 for low-high)

- Timescale/ milestones (2 points possible: 0 for none, 1-2 for immediate to long-term goals)

- Fitting investment criteria (2 points possible, 1 for cleantech match, 1 for technology match)

(5) Management Experience

\section{Indicators:}

a. Founding member/CEO's level of experience with previous startup building or scaling

b. Founding member/CEO's level of experience with hardtech startups

c. Founding member/CEO's level of experience with cleantech

d. Founding member/CEO's level of experience in core technology's industry 


\section{Scoring system:}

Index score out of 8:

- Previous startup experience (3 points possible: 0 for none, 1-3 for low-high)

- Industry experience (3 points possible: 0 for none, 1-3 for low-high)

- Hardtech experience (1 point possible)

- Cleantech experience (1 point possible)

(6) Non-financial Support

\section{Indicators:}

a. Whether the firm's investors have an existing network in either cleantech of the firm's type of core technology

b. Presence or absence of an effective alliance network through university lab, philanthropic investors, fellowship programs, or incubator programs

c. Number of types of support used, including lab access, legal assistance, access to investor network, and access to experts or opinion leaders

\section{Scoring system:}

Index score out of 8:

- Investor network (2 points possible, 1 for cleantech match, 1 for technology match)

- Effective alliance network (3 points possible: 0 for none, 1-3 for low-high)

- Low to high scoring is relative to other cases, using a total counts for: university labs, philanthropic investors, fellowship programs, incubator programs

- Types of support used (3 points possible: 0 for none, 1-3 for low-high)

- Low to high scoring is relative to other cases, using a total counts for: lab access, legal assistance, access to investor network, and access to experts or opinion leaders 


\section{(7) Straightforward Development Path}

\section{$\underline{\text { Indicators }}$}

a. $\quad$ Self-reported number of pivots

b. Whether the pivot occurred early or late in development

c. Self-report of whether the pivots were considered minor or major

d. Self-report of whether the pivots were expected or unexpected

\section{Scoring system:}

Index score out of 8 :

- If no pivots: 8 points

- For $\geq 1$ pivots: Number of pivots score + Average characteristic score for all pivots recorded

- Number of pivots ( 2 points possible: 0 points for $>2$ pivots, 1 point for 2 pivots, 2 points for only 1 pivot)

- Characteristic score for each pivot: Sub-index score out of 6:

- When pivot occurred (2 points possible: 0-2 for late, min, early)

- Major or Minor (2 points possible: 0-2 for major, mid, minor)

- Expected or unexpected (2 points possible: 0-2 for unexpected, somewhat expected, completely expected)

\section{Appendix B. Final Question List for Semi-Structured Interviews}

\section{B1.Company Identification and Conditions of Exit}

- Tell us a bit about your company

- What was your core technology? What was your product? 
- What year was your company established?

- Can you tell us more about the conditions of your exit?

- Who were the buyers

- (ADDITIONAL) Why did they buy it?

- (ADDITIONAL) What has happened to the technology since?

\section{B2.Favorable Industry}

- Walk me through the context of your startup development- the atmosphere, the timing, public opinion, etc.

- If interviewee thinks their startup developed in a favorable context, why/ what element made it so? (don't prompt, but try to tease out)

- Were consumers adopting/ demanding for that technology?

- Was there policy support or regulatory changes (government providing subsidies to consumer/ companies, new regulations that might influence industry practice/ consumer practice)?

- Were there large companies buying technology at that time?

- (ADDITIONAL) Timeline of these conditions

\section{B3.Commercial Readiness}

OUT OF 5 CATEGORIES, ask them to pick for each:

\begin{tabular}{|c|c|c|c|c|}
\hline Category 1 & Category 2 & Category 3 & Category 4 & Category 5 \\
\hline $\begin{array}{l}(\mathrm{TRL}<=3) \text { Basic } \\
\text { principle/ } \\
\text { technology } \\
\text { concept or } \\
\text { application } \\
\text { formed, up until } \\
\text { Proof of concept }\end{array}$ & $\begin{array}{l}\left(\begin{array}{ll}T R L & 4\end{array}\right) \text { lab- } \\
\text { scale validation }\end{array}$ & $\left.\begin{array}{ll}(\text { TRL } & 5\end{array}\right)$ & $\begin{array}{l}\text { (TRL 6-7) } \\
\text { Prototype } \\
\text { demonstrated in } \\
\text { relevant } \\
\text { environment or } \\
\text { actual } \\
\text { operational } \\
\text { environment }\end{array}$ & $\begin{array}{l}(\text { TRL }>=8) \\
\text { System complete } \\
\text { and qualified or } \\
\text { actual system } \\
\text { proven }\end{array}$ \\
\hline
\end{tabular}


- How long after starting your company did you approach investors for the first time? Where was your technology at that time (prompt the 5 categories)?

- How long after approaching investors for the first time was the first investment made? Where was your technology at that time (prompt 5 categories)?

- How long after first investment did your company exit? Where was your technology at that time (prompt 5 categories)?

\section{B4. Visibility to Potential Investors}

- Where is your startup based? (include technology, product, manufacturing, etc)

- How did you meet potential investors?

- What was the interviewee's participation in the following (prompt if necessary, but first try to tease out)

○ Networking events?

- Competitions? If competitions, did they win?

○ Fellowships?

$\circ$ Anything else?

- How many of the above did the interviewee participate in?

- (ADDITIONAL) If you had to rank the different methods discussed above, which would you say was the most important in reaching potential investors?

- (ADDITIONAL) Talk us through your process for finding potential investors. Was finding the right investors for you challenging? Why/why not?

\section{B5.Interaction with Actual Investors}

- Now, we'd like to discuss your interactions with your actual investors. Who were your investors? Professional investors or friends or strategics? Did your initial investors invest in other cleantech companies?

- How frequently did you meet with your investors (Average times per week)? (Encourage interviewee to give us their best estimate)

- In your interaction with your investors, what time-horizon or milestones framed your discussions? (Try to get an answer without specifying an example. If the interviewee is 
confused, you can say: "For example, when you were in Proof of Concept phase, were most of your discussions focused on demonstration? Did you guys discuss all the way to commercialization?")

- Did you clearly understand the priorities of your investors? Did you ever try to address these criteria specifically?

- (ADDITIONAL) How much capital did you raise?

\section{B6.Non-financial Support}

- (Choose multiple) Did your company partner with: a university lab, philanthropic investor, fellowship program, incubator program, other, none?

- How were these relationships? What kind of support, if at all, were you offered from each? (prompt if necessary, but also ask "anything else"?)

- lab space

- network with investors

- legal support

○ network with non-investors including academics/ experts/ industry leaders/ influencers)

$\circ$ Anything else?

- How helpful, if at all, were these to your startup?

- (ADDITIONAL) How much do you think each of these partnerships affected investor perception of/ confidence in your firm?

\section{B7.Straightforward Development Path}

- Talk me through your company's development path. Did you have to make strategic changes?

- If yes, at what stage did this/ each change occur (early or late)?

- Was this strategic change expected or unexpected?

- If yes, would you say this/ each change was minor or major? 


\section{B8. Management Experience}

- Have you built a startup before?

- How did your team evolve throughout your startup, up until the exit?

- Did any have past experiences building their own company or growing another startup? (focus on asking about past experiences and \#ppl)

- For each person: what did they do in that previous company (role, time at company)?

\section{B9. Conclusion}

- (ADDITIONAL) What do you think hardtech startups need?

- Is there anything we haven't covered that we should know?

- Do you have any questions for us? 